NBER WORKING PAPER SERIES

\title{
GLOBALIZATION AND THE GAINS FROM VARIETY
}

\author{
Christian Broda \\ David E. Weinstein \\ Working Paper 10314 \\ http://www.nber.org/papers/w10314 \\ NATIONAL BUREAU OF ECONOMIC RESEARCH \\ 1050 Massachusetts Avenue \\ Cambridge, MA 02138 \\ February 2004
}

We would to thank Alan Deardorff, Robert Feenstra, Jonathan Eaton, Amartya Lahiri, Mary Amiti, and Kei$\mathrm{Mu}$ Yi for excellent comments and suggestions. Rachel Polimeni provided us with outstanding research assistance. David Weinstein was at the Federal Reserve Bank of New York when most of this research was done. In addition, he would like to thank the Center for Japanese Economy and Business for research support. The views expressed herein are those of the authors and not necessarily those of the National Bureau of Economic Research.

C2004 by Christian Broda and David E. Weinstein. All rights reserved. Short sections of text, not to exceed two paragraphs, may be quoted without explicit permission provided that full credit, including $\mathbb{C}$ notice, is given to the source. 
Globalization and the Gains from Variety

Christian Broda and David E. Weinstein

NBER Working Paper No. 10314

February 2004

JEL No. F1, E3

\title{
$\underline{\text { ABSTRACT }}$
}

Since the seminal work of Krugman (1979), product variety has played a central role in models of trade and growth. In spite of the general use of love-of-variety models, there has been no systematic study of how the import of new varieties has contributed to national welfare gains in the United States. In this paper we show that the unmeasured growth in product variety from US imports has been an important source of gains from trade over the last three decades (1972-2001). Using extremely disaggregated data, we show that the number of imported product varieties has increased by a factor of four. We also estimate the elasticities of substitution for each available category at the same level of aggregation, and describe their behavior across time and SITC-5 industries. Using these estimates we develop an exact price index and find that the upward bias in the conventional import price index is approximately 1.2 percent per year. The magnitude of this bias suggests that the welfare gains from variety growth in imports alone are 2.8 percent of GDP.

\author{
Christian Broda \\ Federal Reserve Bank of New York \\ christian.broda@ny.frb.org \\ David E. Weinstein \\ Columbia University, Department of Economics \\ 420 W. 118th Street \\ MC 3308 \\ New York, NY 10027 \\ and NBER \\ dew35@columbia.edu
}




\section{Globalization and the Gains from Variety}

\section{I) Introduction}

It is striking that in the quarter-century since Krugman (1979) revolutionized

international trade theory by modeling how countries could gain from trade through the import of new varieties, no one has structurally estimated the impact of increased variety on aggregate welfare. As a result, our understanding of the importance of new trade theory for national welfare rests on conjecture, calibration, and case studies. This paper represents the first attempt to provide an answer to the question of how much increases in traded varieties matter for the US. Analyzing the most disaggregated US import data available for the period between 1972 and 2001, we find that consumers have low elasticities of substitution across similar goods produced in different countries. This establishes the reasonableness of a key assumption underlying the Dixit-Stiglitz (1977) framework - namely, that consumers value variety. Moreover, we find that the four-fold increase in available global varieties arising in the last 30 years has produced a large welfare gain for the United States. Increases in imported varieties have raised US real income by about 3 percent. In short, our results provide stunning confirmation of the importance of thinking about international trade within the Dixit-Stiglitz framework.

In order to generate these point estimates, our work makes contributions to a number of literatures. The first is toward the measurement of prices. One of the major problems confronting economists is how to build an aggregate price index that allows for the creation of new goods and varieties. While there is general agreement that this is important, efforts to accomplish it 
have proved elusive. ${ }^{1}$ As a result, economists have taken two approaches to the problem, neither of which is ultimately satisfying. Following the pioneering work of Hausman (1981), one strategy has been to estimate the price drop implied by the existence of an individual new good, e.g. Apple-Cinnamon Cheerios. A second approach is to make extreme assumptions about how new goods are valued, e.g. all varieties enter into utility virtually identically (Romer (1994)). Unfortunately, the extreme data requirements of the Hausman methodology has limited its application to only a handful of goods while the extreme assumptions of the second approach raise questions about the validity of the calculations.

The starting point for our analysis is the seminal work of Feenstra (1994). In this paper, Feenstra develops a robust and easily implementable methodology for measuring the impact of new varieties on an exact price index of a single good using only the data available in a typical trade database. Unfortunately, his approach has two drawbacks that have prevented researchers from adopting it more widely. First, it is computationally extremely intensive. As a result, Feenstra only applied the methodology to 8 goods - far fewer than the 30,000 necessary to reconstruct the US import price index over the last 30 years. Second, Feenstra's methodology tends to generate a large number of elasticities that take on imaginary values, which are hard to interpret. This paper solves both problems - the first through higher processor speed and the second by modifying Feenstra's estimation strategy - and demonstrates the relative ease with which the Feenstra sub-indexes can be used to compute an aggregate price index.

To calculate an aggregate import price index, we first have to estimate a number of parameters that are of wide interest. This constitutes our second contribution. In particular, we

\footnotetext{
${ }^{1}$ For example, Charles Shultze (2003, p. 19) writes, "The [National Academy of Sciences panel on the CPI] recognized that research into the welfare effects associated with new goods is important and should be pursued. But it emphasized the immense practical difficulties in the way of providing estimates of demand curves and virtual prices, especially if done across the large number and wide variety of products that would be required."
} 
estimate elasticities of substitution among goods at various levels of aggregation. At the lowest level of aggregation available for trade data (8-digit for 1972-1988 and 10-digit for 1990-2001) we estimate almost 30,000 elasticities. This enables us to directly test a number of important stylized facts. For example, we directly demonstrate the validity of Rauch's (1999) conjecture that goods traded on organized exchanges are indeed more substitutable than those which are not. We are able to document that varieties appear to be closer substitutes the more disaggregate the product category. We also find that the median elasticity of substitution has fallen over time indicating that traded goods have become more differentiated. In sum, we develop the most comprehensive examination of elasticities of substitution that has ever been attempted.

We then use these estimated parameters to reconstruct the US import price index while hewing very closely to theory. Starting with the constant elasticity of substitution utility function which underlies the Spence-Dixit-Stiglitz (henceforth SDS) framework, we compute an exact aggregate price index for the CES utility function that allows for changes in varieties. Since this is the same assumption that is used in much of the new trade theory, economic geography, and growth literatures (Helpman and Krugman (1985), Grossman and Helpman (1991), Fujita, Krugman, and Venables (1999)), our estimates can be directly applied to these literatures. Our results suggest that the impact of increased choice on an exact price index has been enormous. Whereas previous authors have found small changes in import prices and the terms of trade as a result of variety changes, our study finds that price indices that do not take new and disappearing varieties into account seriously overestimate import price increases. Over the last thirty years, if one adjusts for new varieties, import prices have been falling 1.2 percent per year faster than one would surmise from official statistics. In aggregate terms this means that the aggregate price 
index that takes variety changes into account has fallen by 28.1 percent relative to the conventionally measured import price index.

Finally, we are able to use this price decline to obtain an estimate of the gains from new imported varieties under the same structural assumptions as Krugman (1980). This massive drop in our correctly measured price of imports drives our estimate of the gains from globalization. The 28 percent drop in import prices due to new varieties alone implies that increases in imported varieties have raised US welfare by about 3\%. In sum, our results show that, when measured correctly, increases in imported varieties have had a large positive impact on US welfare.

\section{II) Prior Work}

What is a variety? Previous work has not answered this question with a unified voice. In terms of theory, a variety is commonly defined as a brand produced by a firm, the total output of a firm, the output of a country, or the output within an industry within a county. As a result of the variety of definitions of variety, empirical papers are often not strictly comparable. For example, econometric case studies typically define a variety as a product line produced by a firm; many international trade papers define a variety as a disaggregated trade flow from a particular country; and other papers have defined a variety either as firm- or plant-level output. The choices are often driven by data availability and the types of theories that the researchers are examining. While we will make precise our definition of variety later, we want to emphasize that as we discuss prior work, the definition of variety will vary across papers.

Several studies have attempted to measure the impact of new varieties on welfare for individual goods and at the aggregate level. Hausman (1981) pioneered what is probably the 
most detailed approach to estimating the gains from new varieties (product line) of an individual good. He develops a closed-form solution to estimating linear and log-linear demands and calculates the new product's 'virtual price', the price that sets its demand to zero. Based on this estimate and on the current price, he calculates the welfare change that results from the price drop of the new product (e.g., Hausman (1997) for breakfast cereals, Petrin (2001) for minivans, and Brynjolfsson et al. (2003) for online books among others ${ }^{2}$ ). The advantage of this approach is that by taking enormous care to model, for example, the market for Apple Cinnamon Cheerios, one can obtain extremely precise estimates that can take into account rich demand and supply interactions. However, the data requirements to implement this approach for the tens of thousands of goods that compose an aggregate price index are simply insurmountable. For this reason, it is not surprising that no one has attempted to estimate aggregate gains from new products using this approach.

At the aggregate level, all existing studies rely on calibration or simulation exercises to measure the effect of variety growth. These studies typically define a variety as the imports from a given country or the imports from a given country in a particular industry. These studies typically do not focus on how varieties affect prices but rather provide some interesting calculations about potential welfare effects. Feenstra (1992) and Romer (1994), for example, provide numerical exercises showing that the gains from new varieties from small tariff changes can be substantial. Klenow and Rodriguez-Clare (1997) calibrate a model of the impact of trade liberalization on Costa Rica and find only modest gains. They suggest that the low elasticity of

\footnotetext{
${ }^{2}$ Several other recent papers using micro data have focused on the welfare consequences of the introduction of a single product. These papers include Trajtenberg (1989), Bresnahan and Gordon (1997), Berry, Levinsohn and Pakes (1993, 1995) and Hausman (1997, 1998).
} 
substitution and large import shares used in Romer (1994) account for the difference in welfare gains. $^{3,4}$

These papers have provided an invaluable first step in understanding how to move from theory to data, but they suffer from a number of problems, as they require a large number of restrictive simplifying assumptions in order to obtain the estimates. For example, these papers use one or at most two elasticities of substitution in order to value varieties. ${ }^{5}$ This creates three types of problems. The first arises from assuming that all elasticities of substitution are the same for varieties of different goods. Since presumably consumers care more about varieties of computers than crude oil, it is not clear that all increases in imports correspond to the same gains from increased variety. The second problem arises from assuming that the elasticity of substitution across goods equals that across countries providing the same good. Presumably we care more about the amount of gasoline we import than about the number of sources of that gasoline. The final and perhaps largest problem arises from assuming that all varieties enter into the utility function with a common elasticity. When one is estimating a parameter that is averaging together, say, the impact of an increase of Saudi Arabian oil prices on Mexican oil imports and Japanese car imports, it is hard to interpret the meaning of the elasticity or have intuition for its magnitude.

\footnotetext{
${ }^{3}$ Rutherford and Tarr (2002) simulate a growth model with intermediate input varieties that magnifies the effect of trade liberalization on welfare, and suggest that a $10 \%$ tariff cut can lead, in the long run, to welfare gains of roughly $10 \%$. A key aspect of the model is the elasticity of transformation between domestic output and exports. With trade balance, a higher elasticity implies that imports (and exports) will increase substantially as the real exchange rate depreciates following a fall in tariffs.

${ }^{4}$ Hummels and Klenow (2002) define indices of intensive and extensive margins for US exports, and examine the ability of several models to match the data.

${ }^{5}$ The most disaggregated estimates of elasticities of substitution that we have found for a wide range of goods are those done by Hummels (1999). He estimates elasticities for around 100 goods, but does not use these to generate a price index or do welfare analysis. Yet even with 100 goods, categories contain many different goods. For example, road vehicles are made up of many different types of goods -- passenger cars, wheelchairs, trucks, bicycles, and tractors are all categorized as "road vehicles".
} 
A different class of problem with calibration exercises stems from the choice of the parameter values and the use of symmetric utility functions. Parameter values, such as elasticities of substitution, are often chosen arbitrarily or are estimated from one dataset and applied to another dataset. An important feature of our study is that all parameters are estimated directly from the relevant data and not chosen in order to obtain sensible values for some other stage of the analysis. Moreover, in the case of a symmetric utility function, since all varieties are valued alike a count of the number of imported varieties is sufficient to perform welfare calculations. This approach is only valid under the extreme symmetry assumptions underlying the particular utility function used. Indeed, this paper shows that the use of count data, rather than the changes in import volumes as suggested by Feenstra (1994), can be highly misleading as a measure of variety growth if one allows for a more general utility function.

The third problem is related to the way in which previous studies have estimated the single elasticity of substitution. By far the simplest of these approaches is to estimate the elasticity of substitution by regressing bilateral trade flows on various control variables and a measure of trade costs (e.g., Romer (1994) and Hummels (1999)). The coefficient on trade costs is used as the elasticity of substitution among varieties. The major problem with this approach is that one needs to make extreme identifying assumptions in order to ignore simultaneity problems. Chief among these is the assumption that trade costs are completely passed through to consumers. This assumption is almost surely inappropriate for the US and the other large importers who together account for the majority of world trade. A second problematic identifying assumption is that movements in trade costs are unaffected by movements in import demand. Unfortunately, this assumption will be violated whenever per unit transport costs are a function of import volumes, countries care about import responses when cutting bilateral tariffs, 
or movements in non-tariff barriers are correlated with movements in tariffs. Since all of these conditions are likely to be violated in reality, the estimated elasticities are problematic.

Our paper proceeds as follows. In Section III we provide an overview of the basic theoretical contributions on the literature of variety growth and the reasons behind the structure we use in this paper. In Section IV we provide descriptive statistics on the growth in varieties in US imports since 1972. Section V is devoted to the methodology used to compute an exact price index and to estimate elasticities of substitution that correct for endogeneity bias, measurement error, and that allow for changes in taste and quality parameters. Section VI presents the main results of the paper. We present our conclusions in Section VII.

\section{III) Theory: Why do varieties matter?}

All studies that seek to quantify the potential gains from variety are forced to impose some structure on how varieties might affect welfare. Theorists have proposed many ways of modeling this (see, for example, Hotelling (1929), Lancaster (1975), Spence (1976) and Dixit and Stiglitz (1977)), and the assumptions underlying these models are not innocuous. As empirical researchers, we are forced to choose from a number of plausible theories. Our choice of the Spence-Dixit-Stiglitz (SDS) framework is based on three criteria: prominence, tractability, and empirical feasibility.

There is little question that in international trade, economic geography, and macroeconomics, the SDS framework is the preferred way of specifying how consumers value variety. A major reason for this stems from the tractability of the CES utility function and its close cousin, the Cobb-Douglas. In addition to the work of Krugman, the Dornbush, Fisher, Samuelson models and more recent work by Eaton and Kortum (2002) all use CES and Cobb- 
Douglas functions. Hence, it is quite natural to use this preference structure as the basis of our empirical work. At the very least, our work provides a useful benchmark for thinking about the potential gains from imported varieties within this framework.

A second reason to base our work on the SDS framework is theoretical tractability. As Helpman and Krugman [(1985) pp. 124-129] note, preference systems based on the Hotelling and Lancaster models do not easily lend themselves to the creation of aggregate price indexes or utility functions when there is more than one market in the economy. Since one of the main objectives of this study is to build an aggregate price index, we need to use a theoretical structure that will let us aggregate price changes across markets.

Finally, the CES satisfies another important characteristic - empirical feasibility. Demand systems based on CES utility functions are relatively easy to estimate. This is of paramount importance since we need to be able to aggregate estimates of the gains from variety in tens of thousands of markets. Moreover, since we know next to nothing about demand and supply conditions in virtually all of the markets we examine, it is simply not feasible to implement a more complex supply and demand structure. ${ }^{6}$ Thus, although one would ideally like to control for all of the complexities present in international markets, data limitations and the shear time required to perform a careful analysis of all of these markets makes this impossible in practice.

Given our structure for how we model the way in which consumers value variety, we now need to be precise about what we mean by a variety. Our reliance on the Krugman (1980) structure might suggest that we adopt a definition of variety that is based on firm-level exports. Unfortunately there are a number of problems with taking this literal approach to the data. First,

\footnotetext{
${ }^{6}$ One undesirable property of the CES is that it imposes the assumption that consumers care about varieties to some extent. In practice, this assumption does not bias our results because an increase in variety will have a trivial impact on prices and welfare if the estimated elasticity of substitution is large.
} 
by treating all imports from a given firm as a single variety one may understate the gains from variety that occur when a firm starts exporting in more than one product line. Second, it is difficult to obtain bilateral firm-level export data for more than a handful of countries. We therefore opt to use the same definition of variety as in Feenstra (1994) - namely, a 8- or 10-digit good produced in a particular country. To give a concrete example, a good constitutes a particular product, e.g. red wine. A variety, however, constitutes the production of a particular good in a particular country, just as in Armington (1969), e.g. French red wine.

Being clear about this distinction highlights an important difference between monopolistic competition models and comparative advantage models that feature a continuum of goods. Both models share the feature that output of tradables is perfectly specialized in equilibrium. However, they differ in terms of how individual varieties are treated. In the comparative advantage continuum of goods models, consumers are indifferent about where a good is produced as long as the price does not vary. In other words, these models assume that holding the good fixed, the elasticity of substitution among varieties is infinite. This is in sharp contrast to the Krugman model that hypothesizes that all firms produce differentiated products and hence the elasticity of substitution should be small.

Despite the sharp theoretical difference, our ability to do precise hypothesis testing is limited. The point estimate for the elasticity of substitution will always be finite and thus we can never formally accept the hypothesis that it is infinite. However, by examining the elasticities of substitution at the 8- or 10-digit level, we can obtain a sense of the degree of substitutability among varieties. If the elasticities of substitution tend to be high, say above 10 or 20 , then this suggests that the potential for gains from variety, a key theoretical result of the monopolistic competition framework, are small. If they are low, then this suggests that even when we use the 
most disaggregated trade data in existence, goods are highly differentiated by country. ${ }^{7}$ Of course, we cannot rule out that if we had even more disaggregated data, we might find a higher estimate of the elasticity of substitution. Yet even so, we do learn something about the world - at the 8- or 10-digit level of aggregation, it is reasonable to think of goods from different countries as far from perfect substitutes. More importantly for our purposes, low elasticities of substitution across varieties are a necessary condition for increases in the number of varieties to be a source of potential gain.

Turning to welfare, the monopolistic competition model described in Krugman (1979 and 1980) suggests two clear channels for the gains from trade arising from variety growth. The first is through reductions in trade costs. If trade costs fall, countries will gain through the import of new varieties. ${ }^{8}$ The second is through growth of the foreign country. As the size of the foreign country rises (which in the Krugman framework is equivalent to a rise in its labor force), it will produce more varieties, and this will also be a source of gain for the home country. These gains are in sharp contrast to the gains postulated by comparative advantage models. In these models, all goods are consumed in equilibrium regardless of the level of trade costs or the size of the foreign country. Hence, in comparative advantage models, all gains from reductions in trade costs or increases in the size of a foreign country are achieved through conventional movements

\footnotetext{
${ }^{7}$ The most disaggregated trade data that we know of is the plant level data collected by the Bureau of the Census. These data sets typically contain data on around 40,000 exporting plants (c.f. Bernard, Eaton, Jenson, and Kortum). By contrast, US 10-digit data recorded 275,000 non-zero export flows for 1989, or seven times higher! This underscores the highly disaggregated nature of our data.

${ }^{8}$ The basic Krugman model predicts that a change in tariffs within non-prohibitive values will not change the number of available varieties although consumers will gain from the falling prices of imported varieties. Romer (1994), however, presents a simple extension of this model to allow for fixed costs of accessing foreign markets so that the number of available varieties rises with a fall in tariffs.
} 
in prices and not through changes in the number of goods. One of the distinguishing features of the Krugman model is that a country may gain from trade even though there are no price changes.

In sum, although theorists have developed a number of models of variety, our choice of the Dixit-Stiglitz structure stems from that model's prominence, tractability, and empirical implementability. Moreover, since this model can easily explain key stylized facts of how the growth of foreign countries and the reduction of international barriers have contributed to an increase in US imports of varieties, we believe it is a particularly appropriate structure to use in order to obtain estimates of the gains from variety.

\section{IV) Data: The Growth of Varieties}

It is well known that trade has been growing faster than GDP for many decades. This process, which is a part of what some term "globalization," has had a profound impact on the dependence of the US economy on foreign goods. Over the last thirty years, the share of imports in US GDP has more than doubled: rising from 4.8 percent in 1972 to 11.5 percent in $2002 .{ }^{9}$ The causes for this explosion in trade stem from a number of sources that have been explored in a vast literature. Most studies attribute the source of the rise to three interrelated causes: reductions in trade costs, relaxations of capital controls (e.g. barriers to foreign direct investment), and the relative growth of many East Asian and other economies outside of the United States.

This rise in US imports has been accompanied by a rise in another phenomenon that has received much less attention - a dramatic rise in imported varieties. Table 1 gives a preliminary overview of the extent of this increase. Between 1972 and 1988, we rely on the Tariff System of

\footnotetext{
${ }^{9}$ Data are from IFS unless stated otherwise.
} 
the United States (TSUSA) 8-digit data and in later years on the 10-digit Harmonized Tariff System (HTS) data (Feenstra (1996) and Feenstra et al. (2002)). We define a good to be an 8- or 10- digit category, and, as mentioned in the previous section, a variety is defined as the import of a particular good from a particular country. ${ }^{10}$ We do not report numbers for 1989 because the unification of Germany means that data for that year are not comparable with later HTS data. ${ }^{11}$

Using our definition of varieties, Table 1 reports that in 1972 the US imported 74,667 varieties (i.e. 7731 goods from an average of 9.7 countries) and in 2001 there were 259,215 varieties (16390 goods from an average of 15.8 countries). Ultimately, we will want to make comparisons across years, and to do that properly we will need to formally deal with a host of issues relating to whether the data for two different years are truly comparable. For now we put these issues aside and focus on the crude measure of variety that we can glean from the sample statistics.

The second column of Table 1 reports the number of goods for which imports exceeded one dollar in a given year. There are two features of this column that are important to note here. First, comparing the values for 1988 and 1990, there appears to be little difference in the number of categories with positive imports in the TSUSA and HTS systems. Second there appears to be a dramatic increase in the number of US import categories over the time periods. Combining the increases over the periods 1972-1988 and 1990 to 2001, it appears that the number of good categories almost doubled. This establishes the importance of thinking about real or apparent new goods or categories when calculating changes in import structure and the price of imports.

\footnotetext{
${ }^{10}$ This definition matters less than one might suppose for our later empirical work since we will estimate elasticities of substitution across varieties of a good and let the data tell us how important differences among varieties are. For the time being, however, we will leave aside the question of how substitutable goods produced in different countries are, and simply focus on the shear number of varieties.

${ }^{11}$ All the countries in the former Soviet Union are aggregated together throughout our analysis.
} 
Columns 3 and 4 report the median and average number of countries exporting a good to the US. These data also reveal a substantial increase in the number of countries supplying each individual good. Between 1972 and 2001, the median number of countries doubled, rising from 6 countries in 1972 to 12 countries today. Similarly, the average number of countries rose 40 percent between 1972 and 1988 and another 30 percent in between 1990 and 2001, resulting in an aggregate increase of 82 percent. In other words, even if we leave aside the issue of why the number of imported categories has increased over time, the data reveal that there has been a dramatic increase in the number of countries supplying each individual good.

This effect can also be seen if we restrict ourselves to the set of goods that were imported at the start and end of each sample period. In rows 3 and 4 of Table 1, we present data on the set of common goods within each sample. The data reveal that the increase in countries supplying these goods was, if anything, even more pronounced than the increase for the sample as a whole. The aggregate increase in the median number of countries supplying common goods was 122 percent, and the average rose 105 percent.

The last two lines provide sample statistics for the set of categories that ceased to exist or appeared during this time period. The data underscore the importance of the birth and death of products. Roughly a third to a half of the categories in which the US recorded positive imports at the start of either period did not contain positive imports at the end of the period. Similarly, somewhere between a third and two thirds of the products imported at the end the two periods were not imported at the start of the sample. Once again, we will have to return to the question of whether this represents the actual birth and death of products or simply product categories, but the table underscores that there are substantial changes in the measured composition of imports across both time periods. 
Taken together, the data in Table 1 suggest that the number of varieties rose 133 percent in the first period and 57 percent in the second period - a total increase of 251 percent. This increase constitutes an almost fourfold increase in the number of varieties over the last three decades. Roughly half of this increase appears to have been driven by a doubling in the number of goods and half by a doubling in the number of countries supplying each good.

The fact that the number of countries supplying each good doubled serves as prima facie evidence of a startling increase in the number of varieties. The most plausible explanations for this rise involve some story of the globalization process coupled with an assumption that goods are differentiated by country (as in Krugman (1980), Romer (1994) and Rutherford and Tarr (2002)). For example, reductions of trade costs may have made it cheaper to source new varieties from different countries. Alternatively, the growth of economies like China, Korea, and India has meant that they now produce more varieties that the US would like to import. But, of course, if these goods are differentiated by country then this implies that there must be some gain from the increase in variety - a point that we will address in the next section.

One can obtain a better sense of the forces that have been driving the increase in variety if we break the data up by exporting country. Table 2 presents data on the numbers of goods exported to the US by country. The first column ranks them from highest to lowest for 1972 and the following columns rank them for subsequent years. Not surprisingly, the countries that export the most varieties to the US tend to be large, high-income, proximate economies. Looking at what has happened to the relative rankings over time, however, reveals a number of interesting stylized facts. First, Canada and Mexico have risen sharply in the rankings. Canada moved from being the fourth largest source of varieties to first place while Mexico moved from thirteenth to 
eighth place. This may reflect free trade areas and other trade liberalizations between the US and these countries over the last several decades.

Growth perhaps coupled with liberalization also appears to have played some role. Fast growing economies like China and Korea rose dramatically in the rankings. For example, in 1972, China only exported 510 different goods to the US as opposed to 10,199 today. This twenty fold increase in the number of varieties produced a dramatic change in China's relative position: moving from the $28^{\text {th }}$ most important source of varieties in 1972 to the fourth most important today. Similarly, after India began its period of liberalization in the last decade, its growth rate rose sharply as did the number of goods it began exporting. At the other extreme are the economies like Japan and Argentina that have seen fairly substantial drops in the relative number of varieties they export.

The importance of these countries for the growth in available US varieties can be seen in Table 3. The first column presents the ratio of the net change in varieties between 1972 and 1988 from a given country to the change in varieties entering the US as a whole. The second column reports the average share of imports from that country in the first time periods. The third and fourth columns repeat this exercise for the second time period. The table highlights the importance that industrializing Asia has played in creation of new varieties. Particularly prominent is the role played by China. In the first period, China accounted for almost 5 percent of aggregate US variety growth, even though China only accounted for an average of 1 percent of US imports. Other rapidly growing or liberalizing countries, such as Taiwan, Korea, India, and Mexico, also contributed heavily to the increase in available varieties.

Tables 2 and 3 suggest that the increase in varieties was not random. Rather, as foreign countries liberalized and grew, they tended to increase the number of goods they exported to the 
US. The obvious implication of this is that as countries develop and liberalize, they do not simply export more of existing products, but also produce a greater range of differentiated products (see Hummels and Klenow (2002) for a similar empirical result in the cross-section). We will now formally deal with how to correctly measure and value increases in varieties. In particular, we discuss how the methodology used is robust to a host of issues that have been ignored in this descriptive section.

\section{V) Empirical Strategy}

\section{a) The Feenstra Price Index}

In this section, we extend Feenstra's (1994) derivation of the exact price index of a single CES aggregate good that allows for both new varieties and taste or quality changes in existing varieties, to the case of several CES aggregate goods. We show that the aggregate bias that results from ignoring new varieties depends on their share relative to existing varieties (and not on the actual number of new varieties per good), the goods' weight in total consumption, and the elasticity of substitution between the varieties of each different good (and not on the elasticity of substitution between goods).

The first step towards deriving an aggregate exact price index is a utility function over all goods available for consumption. Suppose that the preferences of a representative agent can be denoted by a two-level utility function (as in Helpman and Krugman (1996), Ch.6)

$$
U\left(D_{t}, M_{1 t}, \ldots, M_{N_{t} t}\right)=\left(\sum_{g \in G_{t}}\left(b_{g t}^{\frac{1}{\gamma}} M_{g t}^{\frac{\gamma-1}{\gamma}}\right)^{\frac{\gamma}{\gamma-1}}\right)^{1-\alpha} D_{t}^{\alpha} ; \gamma>1
$$

where $M_{g t}$ is the sub-utility derived from the consumption of imported good $g$ in time $t, \gamma$ denotes the elasticity of substitution among imported goods, and $D_{t}$ is a composite domestic 
good; $G_{t} \subset\left\{1, \ldots, N_{t}\right\}$ is the set of imported goods available in period $t ; b_{g t}>0$ denotes a taste parameter for good $g$, which is allowed to vary over time.

A particularly useful form of $M_{g t}$ is the non-symmetrical CES function, which can be represented by

$$
M_{g t}=\sum_{c \in C_{g t}}\left(d_{g c t}^{\frac{1}{\sigma_{g}}}\left(m_{g c t}\right)^{\frac{\sigma_{g}-1}{\sigma_{g}}}\right)^{\frac{\sigma_{g}}{\sigma_{g}-1}} \quad ; \sigma_{g}>1 \quad \forall g \in G_{t}
$$

where $\sigma_{g}$ is the elasticity of substitution among varieties of good $g$, which is assumed to exceed unity; for each good, imports are treated as differentiated across countries of supply, $c$ (as in Armington (1969)). ${ }^{12}$ That is, we identify varieties of import good $g$ with their countries of origin. $C_{g t} \subset\left\{1, \ldots, V_{g t}\right\}$ is the set of countries in period $t$ that supply good $g ; V_{g t}$ is the number of countries supplying good $\mathrm{g}$ in time $t ; d_{g c t}$ denotes a taste or quality parameter for good $g$ from country $c$. As in Feenstra (1994), a rise in $d_{g c t}$ raises the demand for good $g$ from country $c$ (see section 2).

The next step towards computing exact price indices is to obtain the minimum unit-cost functions for the preferences defined above. ${ }^{13}$ For the sub-utility function in (2) the minimum unit-cost function is given by

$$
\phi_{g t}^{M}\left(C_{g t}, \mathbf{d}_{g t}\right)=\left(\sum_{c \in C_{g t}} d_{g c t}\left(p_{g c t}\right)^{1-\sigma_{g}}\right)^{\frac{1}{1-\sigma_{g}}}
$$

\footnotetext{
${ }^{12}$ One of the features and limitations of the CES functional form is that the elasticity of substitution plays a dual role as a measure of substitution across varieties and a key factor in evaluating new varieties. This functional form assumption makes the CES attractive for theoretical and empirical researchers but one can contemplate more complex relationships. Brown, Deardorff, and Stern (1995) calibrate a model with variety growth using a more general CES function.

${ }_{13}$ The minimum cost function is defined as the minimum expenditure required to buy one unit of the bundle of imported goods, $M_{g t}$, given the prices of the different import goods.
} 
where $p_{g c t}$ is the price of variety $c$ of good $g$ in period $t$ and $\mathbf{d}_{g t}$ is the vector of taste or quality parameters for each country. Note that (3) can be used to illustrate the essence of the love-ofvariety approach and the source of deficiencies in conventional price indices. Suppose that $V_{g}$ varieties of good $g$ are available to consumers and that $d_{g c}=1 \forall c \in C_{g}$ (i.e., $M_{g}$ is symmetric). Then in a standard monopolistic competition model all varieties will be equally priced at $p_{g}$. In this case, the minimum unit-cost function becomes $\phi_{g}^{M}=V_{g}^{\frac{1}{1-\sigma_{g}}} p_{g}$. For a given $p_{g}$, an increase in $V_{g}$ implies that the minimum cost required to achieve a given level of utility falls, and therefore as variety increases utility rises. However, a conventional price index that does not consider new varieties will not capture the fall in minimum unit-costs, or equivalently, the rise in utility.

The minimum cost function of (1), in turn, can be denoted by

$$
\phi_{t}\left(\phi_{1 t}^{M}, \ldots, \phi_{N_{t}}^{M}, p_{t}^{D}, C_{t}, \mathbf{b}_{t}\right)=\frac{1}{\alpha^{\alpha}(1-\alpha)^{1-\alpha}}\left(\sum_{g \in G_{t}} b_{g t}\left(\phi_{g t}^{M}\left(C_{g t}\right)\right)^{1-\gamma}\right)^{\frac{1-\alpha}{1-\gamma}}\left(p_{t}^{D}\right)^{\alpha}
$$

where $C_{t}=\left\{C_{1 t}, \ldots C_{N_{t} t}\right\}$, the price of the domestic good is given by $p_{t}^{D}$ and $\mathbf{b}_{t}$ is the vector of taste or quality parameters for each good. Equations (3) and (4) are the main building blocks for the calculation of exact price indices.

We turn next to the derivation of the aggregate bias generated by ignoring new varieties. We proceed in four steps: first, we compute the exact price index for the CES sub-utility function in (2) for a single good, a constant number of varieties and constant taste parameters; second, we review Feenstra's (1994) contribution, namely, to generalize this exact price index to the case of new and disappearing product varieties; third, we derive the aggregate exact price index for (1); and lastly, we provide a description of the extremely useful properties of this aggregate exact price index. 
Suppose that the set of product varieties $C_{g}$ (i.e., supplying countries) that are available in periods $t$ and $t-1$ are the same, and that the taste parameters are constant over time, $d_{g c t}=d_{g c t-1}=d_{g c}$ for $c \in C_{g}$. Also assume that the quantity vectors $\mathbf{x}_{g t}$ and $\mathbf{x}_{g t-l}$ are the costminimizing consumption bundles of good g's varieties given the prices of all varieties, $\mathbf{p}_{g t}$ and $\mathbf{p}_{g t-1}$. In this case, Diewert (1976) defines an exact price index for good $g$ as the ratio of minimum unit costs,

$$
P_{g}\left(\mathbf{p}_{g t}, \mathbf{p}_{g t-1}, \mathbf{x}_{g t}, \mathbf{x}_{g t-1}, C_{g}\right)=\frac{\phi_{g t}^{M}\left(C_{g}, \mathbf{d}_{g}\right)}{\phi_{g t-1}^{M}\left(C_{g}, \mathbf{d}_{g}\right)}
$$

This means that an exact price index has the salient feature that a change in the index exactly matches the change in minimum unit-costs. ${ }^{14}$ As noted by Diewert, a remarkable feature of (5) is that the price index does not depend on the unknown quality parameters $d_{g c}$ for $c \in C_{g}$.

In the case of the CES unit-cost function, Sato (1976) and Vartia (1976) have derived its exact price index,

$$
P_{g}\left(p_{g t}, p_{g t-1}, x_{g t}, x_{g t-1}, C_{g}\right)=\prod_{c \in C_{g}}\left(\frac{p_{g c t}}{p_{g c t-1}}\right)^{w_{g c t}} .
$$

This is the geometric mean of the individual variety price changes, where the weights are ideal log-change weights. ${ }^{15}$ These weights are computed using cost shares, $s_{g c}$, in the two periods, as follows:

$$
s_{g c t}=\frac{p_{g c t} x_{g c t}}{\sum_{c \in C_{g}} p_{g c t} x_{g c t}}
$$

\footnotetext{
${ }^{14}$ Diewert (1976) also presents the dual of (5), where the exact quantity index has to match the change in utility from one period to the other.

${ }^{15}$ As explained in Sato (1976), a price index $P$ that is dual to a quantum index, $Q$, in the sense that $P Q=E$ and shares an identical weighting formula with $Q$ is defined as "ideal". Fischer (1922) was the first to use the term ideal to characterize a price index. He noted that the geometric mean of the Paasche and Laspayres indices are ideal.
} 


$$
w_{g c t}=\frac{\frac{s_{g c t}-s_{g c t-1}}{\ln s_{g c t}-\ln s_{g c t-1}}}{\sum_{g \in C_{g}}\left(\frac{s_{g c t}-s_{g c t-1}}{\ln s_{g c t}-\ln s_{g c t-1}}\right)}
$$

The numerator of (8) is the difference in cost shares over time divided by the difference in logarithmic cost shares over time.

The exact price index of good $g$ in $(5), P_{g}$, requires that all varieties be available in the two periods. Feenstra (1994) showed how to modify this exact price index for the case of different, but overlapping, sets of varieties in the two periods. Suppose that there is a set of varieties $I_{g} \neq \varnothing$ that are available in both periods, and for which the taste parameters are constant. Let $P_{g}\left(\mathbf{p}_{g t}, \mathbf{p}_{g t-1}, \mathbf{s}_{g t}, \mathbf{s}_{g t-1}, I_{g}\right)$ denote the price index in (6) that is computed using data on only this set of goods. As in Feenstra, this is referred to as a "conventional" price index, in the sense that it ignores new and disappearing product varieties. ${ }^{16}$ Proposition 1 states Feenstra's main theoretical contribution, the relationship between the conventional price index and the exact price index that incorporates changes in variety for a single good.

PROPOSITION 1: ${ }^{17}$ For $g \in G_{t}$, if $d_{g c t}=d_{g c t-1}$ for $c \in I_{g}=\left(I_{g t} \cap I_{g t-1}\right), I_{g} \neq \varnothing$, then the exact price index for good $g$ with change in varieties is given by,

\footnotetext{
${ }^{16}$ The BLS constructs a mean of products in the 10-digit category without accounting for different varieties of a given 10-digit product. Other sources of bias between the BLS index and the exact price index of a CES function are: (i) that BLS uses a Laspeyres formula to aggregate to broader industry levels; (ii) BLS takes arithmetic rather than geometric mean; and (iii) BLS uses an unweighted mean.

${ }^{17}$ The appendix of Feenstra (1994) provides the proof of more general proposition, where $c \in I_{g} \subseteq\left(I_{g t} \cap I_{g t-1}\right)$.
} 


$$
\begin{aligned}
\pi_{g}\left(\mathbf{p}_{g t}, \mathbf{p}_{g t-1}, \mathbf{x}_{g t}, \mathbf{x}_{g t-1}, I_{g}\right) & =\frac{\phi_{g t}^{M}\left(I_{g t}, \mathbf{d}_{g}\right)}{\phi_{g t-1}^{M}\left(I_{g t-1}, \mathbf{d}_{g}\right)} \\
& =P_{g}\left(\mathbf{p}_{g t}, \mathbf{p}_{g t-1}, \mathbf{x}_{g t}, \mathbf{x}_{g t-1}, I_{g}\right)\left(\frac{\lambda_{g t}}{\lambda_{g t-1}}\right)^{\frac{1}{\sigma_{g}-1}}
\end{aligned}
$$

where $\lambda_{g t}=\frac{\sum_{c \in I_{g}} p_{g c t} x_{g c t}}{\sum_{c \in I_{g t}} p_{g c t} x_{g c t}}$ and $\lambda_{g t-1}=\frac{\sum_{c \in I_{g}} p_{g c t-1} x_{g c t-1}}{\sum_{c \in I_{g t-1}} p_{g c t-1} x_{g c t-1}}$.

This result states that the exact price index with variety change (i.e., $\pi_{g}\left(I_{g}\right)$ for short) is equal to the conventional price index (i.e., the exact price index of the overlapping varieties, $P_{g}\left(I_{g}\right)$ ), times the additional term $\left(\frac{\lambda_{g t}}{\lambda_{g t-1}}\right)^{\frac{1}{\sigma_{g}-1}} \cdot{ }^{18}$ Note that $\lambda_{g t}$ equals the fraction of expenditure in the varieties that are available in both periods (i.e., $\left.c \in I_{g}=\left(I_{g t} \cap I_{g t-1}\right)\right)$ relative to the entire set of varieties available in period $t$ (i.e., $c \in I_{g t}$ ). Thus, this additional term implies that the higher the expenditure share of new varieties, the lower is $\lambda_{g t}$, and the smaller is the exact price index relative to the conventional price index. In the symmetric case, (9) simply becomes $\pi_{g}\left(I_{g}\right)=P_{g}\left(I_{g}\right)\left(\frac{V_{g t-1}}{V_{g t}}\right)^{\frac{1}{\sigma_{g}-1}}$, and an increase in the number of varieties leads directly to a fall in the exact price index relative to the conventional price index.

\footnotetext{
${ }^{18}$ All of the index numbers used in this paper suffer from the classic "index number problem". In particular, results are dependent on the base year or years used. Since we are examining long-run changes, we use two base years 1972 and 1990.
} 
The Feenstra price index also depends on the good-specific elasticity of substitution, $\sigma_{g}$. As $\sigma_{g}$ grows, the term $\frac{1}{\sigma_{g}-1}$ approaches zero, and the bias term $\left(\frac{\lambda_{g t}}{\lambda_{g t-1}}\right)^{\frac{1}{\sigma_{g}-1}}$ becomes unity. That is, when existing varieties are close substitutes to new or disappearing varieties changes in variety will not have a large effect on the exact price index. By contrast, when $\sigma_{g}$ is small, varieties are not close substitutes, $\frac{1}{\sigma_{g}-1}$ is high, and therefore new varieties are very valuable and disappearing varieties are very costly. In this case, the conventional price index is not appropriate.

Having derived the exact price index with variety change for the sub-utility function in (2), we can now obtain the aggregate exact price index for (1). Assume that the set of imported goods $G$ that are available in periods $t$ and $t-1$ are the same, that there exists a set of varieties $I_{g} \neq \varnothing$ for every $g \in G$, and for which the taste parameters are constant over time, $b_{g t}=b_{g t-1}$ (also define $I=\left\{I_{1}, \ldots, I_{N}\right\}$ ). Also assume that the quantity vectors $\boldsymbol{x}_{t}$ and $\boldsymbol{x}_{t-1}$ are cost minimizing for the prices $\boldsymbol{p}_{t}$ and $\boldsymbol{p}_{t-1}$, respectively. In this case, the aggregate exact price index can be expressed as follows,

$$
\Pi\left(\mathbf{p}_{t}, \mathbf{p}_{t-1}, \mathbf{x}_{t}, \mathbf{x}_{t-1}, I\right)=\frac{\phi_{t}\left(I_{t}, \mathbf{b}\right)}{\phi_{t-1}\left(I_{t-1}, \mathbf{b}\right)}=\left(\prod_{g \in G}\left(\frac{\phi_{g t}^{M}\left(I_{g t}, \mathbf{d}_{g}\right)}{\phi_{g t-1}^{M}\left(I_{g t-1}, \mathbf{d}_{g}\right)}\right)^{w_{g t}(G)}\right)^{1-\alpha}\left(\frac{p_{t}^{D}}{p_{t-1}^{D}}\right)^{\alpha}
$$

where the second equality follows from applying (6) to the CES bundle of imported goods, and Samuelson (1965). By replacing (5) and (9) in (10), we obtain the relationship between the aggregate conventional price index $(C P I)$ and the aggregate exact price index: 


$$
\Pi(I)=\left(\prod_{g \in G}\left(P\left(I_{g}\right)\left(\frac{\lambda_{g t}}{\lambda_{g t-1}}\right)^{\frac{1}{\sigma_{g}-1}}\right)^{w_{g t}(G)}\right)^{1-\alpha}\left(\frac{p_{t}^{D}}{p_{t-1}^{D}}\right)^{\alpha}
$$

(11)

$$
=C P I(I)\left(\prod_{g \in G}\left(\frac{\lambda_{g t}}{\lambda_{g t-1}}\right)^{\frac{w_{g t}(G)}{\sigma_{g}-1}}\right)^{1-\alpha}
$$

where the aggregate bias that would have resulted from ignoring new varieties in all product categories is given by:

$$
\frac{\Pi(I)}{C P I(I)}=\left(\prod_{g \in G}\left(\frac{\lambda_{g t}}{\lambda_{g t-1}}\right)^{\frac{w_{g t}(G)}{\sigma_{g}-1}}\right)^{1-\alpha}
$$

The empirical measurement of (12) is the focus of the empirical section that follows and represents the main contribution of this paper.

Basing an aggregate price index on the Feenstra price index corrects a host of problems that plagued prior work. First, our theoretical framework allows varieties to account for different shares of expenditures due to quality or taste differences. This is in sharp contrast with prior work on measuring variety growth, which replace our lambda ratio, $\frac{\lambda_{g t}}{\lambda_{g t-1}}$, with the ratio of the number of varieties in each period, $\frac{V_{g t-1}}{V_{g t}}$. As equation (11) suggests, replacing the lambda ratio with the ratio of the number of varieties in the two periods can yield substantial biases. These "quality biases" can be quite large. For example, if new varieties represent only a small (large) share of the total expenditure in a good, then a simple count of varieties will grossly overestimate (underestimate) the true impact of new varieties. 
Second, we eliminate the "symmetry bias" arising from assuming that all varieties are interchangeable. As equation (11) indicates, the correct price index should allow for elasticities of substitution among varieties of different goods to vary. This implies that the same increase in price of a variety of two different goods may be valued differently by consumers. Thus, measuring the aggregate bias requires that these elasticities of substitution be estimated (this is the focus of the next section). In other words we do not require that $w_{g t}(G)$ or $\sigma_{g}$ be the same for all goods. Moreover, since we have a two-tiered CES utility function, we do not require that the elasticity of substitution among varieties be the same as that across goods. ${ }^{19}$

Third, because our aggregate price index is based on the Feenstra index, it is robust to a wide variety of data problems arising from the creation and destruction of product categories $g$. For example, if goods are randomly split or merged, then the index remains unchanged. ${ }^{20} \mathrm{By}$ contrast, a measure based on the number of varieties would erroneously register a fall or rise in the price level. Similarly, it can be shown that if categories are split when a product category becomes large and merged when it becomes small, then the index also will remain unchanged. ${ }^{21}$ Finally our index is also robust to the possibility that there may be more than one variety contained in the imports from a given country of an 8- or 10-digit good. ${ }^{22}$

\footnotetext{
${ }^{19}$ We do require, however, that the elasticity of substitution between goods be the same.

${ }^{20}$ A simple example can help understand the intuition of this result Assume that there are two varieties (1 and 2) of good $g$ in period $t-1$, and $p_{g 1 t-1} q_{g t-1}=p_{g 2 t-1} q_{g 2 t-1}=5$. In period $t$, the consumption of variety 1 remains unchanged but variety 2 splits into varieties 3 and 4 , and consumption is given by $p_{g 2 t} q_{g 2 t}=0, p_{g 3 t} q_{g 3 t}=2, p_{g 4 t} q_{g 4 t}=3$. It is easy to show that our measure of the price movement arising from new varieties, $\left(\lambda_{g t} / \lambda_{g t-1}\right)^{1 /\left(\sigma_{g}-1\right)}$, is unaffected (as it should be). Similarly, we can show that if the number of goods categories increases, our index will not change. Note also that if the number of varieties were used instead of the shares, the index would fall from 1 to $2 / 3$.

${ }^{21}$ The proof is available from the authors. It is possible to have a bias if statistical agencies split categories that grow but never destroy old categories. However, if this were true, we should observe the average imports per category falling over time rather than the relatively constant size of categories that we actually see.

${ }^{22}$ Feenstra (1994) shows that the effects of multi-variety per product-country pair acts in the same way as a change in the taste parameter or quality parameter for that country's imports.
} 


\section{b) Identification and Estimation of the Elasticity of Substitution}

In order to estimate the impact of new imported varieties on the price index we first need to obtain estimates of the elasticity of substitution between varieties of each good. In this section we present a simple model of import demand and supply equations to estimate this elasticity of substitution. We use the estimation method by Feenstra (1994) that provides an estimate robust to the simultaneity bias that is common in demand and supply systems and to measurement error from using unit values that are not proper price indices. The estimator also allows for random changes in the taste parameters of imports by country. We examine a limitation of this method when applied to a broad set of goods, and provide a solution to dealing with this limitation empirically.

\section{i) Import Demand and Supply}

The simple demand and supply system used can be described by

$$
\begin{gathered}
x_{g c t}=\left(\frac{p_{g c t}}{\phi_{g t}^{M}\left(b_{t}\right)}\right)^{1-\sigma_{g}} \frac{d_{g c t} E_{g t}}{p_{g c t}} \\
p_{g c t}=\exp \left(v_{g c t}\right) x_{g c t}^{\omega_{g}}
\end{gathered}
$$

where equation (13) is the demand for good $g$ and country $c$ derived from the sub-utility function in (2), and $E_{g c t}=\sum_{c \in C_{g t}} p_{g c t} x_{g c t} \cdot{ }^{23}$ Equation (14) describes the supply curve for imports from country $c, \omega_{g} \geq 0$ is the inverse supply elasticity (assumed to be the same across countries) and $v_{g c t}$ captures a random technology factor that is assumed independent from $d_{g c t}$. 
As noted by Kemp (1962), using expenditure shares instead of physical quantities in the system in (13)-(14) reduces the measurement error in the import prices related to the use of unit values. Unlike physical quantities, expenditure shares should not be correlated with the measurement error in the unit values. For this reason we use (7) to express (13) in terms of shares. Following Feenstra (1994), we write (13) in a form more convenient for estimation, we take logs, first difference, and treat $\varepsilon_{g c t}$ as an error term in the demand equation, ${ }^{24}$ which yields

$$
\Delta \ln s_{g c t}=\varphi_{g t}-\left(\sigma_{g}-1\right) \Delta \ln p_{g c t}+\varepsilon_{g c t}
$$

where $\varphi_{g t}=\left(\sigma_{g}-1\right) \ln \left[\frac{\phi_{g, t}^{M}\left(b_{t}\right)}{\phi_{g, t-1}^{M}\left(b_{t-1}\right)}\right]$ is a random effect as $\boldsymbol{b}_{t}$ is random.

Taking logs and first differences of (14) we obtain $\Delta \ln p_{g c t}=\omega_{g} \Delta \ln x_{g c t}+v_{g c t}$, and using the definition of shares together with (15) yields

$$
\Delta \ln p_{g c t}=\psi_{g t}+\rho_{g} \frac{\varepsilon_{g c t}}{\sigma_{g}-1}+\delta_{g c t} ; 0 \leq \rho_{g}<1
$$

where $\psi_{g t}=\omega_{g}\left(\varphi_{g t}+\Delta \ln E_{g t}\right) /\left(1+\omega_{g} \sigma_{g}\right)$ is a random term, $\delta_{g c, t}=\left(v_{g c, t}-v_{g c, t-1}\right) /\left(1+\omega_{g} \sigma_{g}\right)$ is the error term which is independent of $\varepsilon_{g c, t}$, and $\rho_{g}=\omega_{g}\left(\sigma_{g}-1\right) /\left(1+\omega_{g} \sigma_{g}\right)$. Note that $\rho_{g}$ captures the correlation between the change in the equilibrium price and a vertical shift of demand of the magnitude $\varepsilon_{g c t} / \sigma_{g}-1$. This coefficient equals zero only when $\omega_{g}=0$, which implies a horizontal supply curve and no simultaneity bias. Thus, equation (16) can be interpreted as a "reduced form" supply curve.

\footnotetext{
${ }^{23}$ Feenstra (1994) shows that when each country's good has several varieties the demand for a country's good is (13) with $d_{g c t}$ replaced with $d_{g c t} \lambda_{g c t} / \lambda_{g c t-1}$.

${ }^{24}$ Even though for some goods $d_{g c t}=d_{g c t-1}$, this error term may not be zero because of a change in the number of varieties of each country (see previous footnote).
} 


\section{ii) Estimation Strategy}

The unusual feature of Feenstra's (1994) method to estimate the system of equations (15) and (16) is that no exogenous variables are needed to identify and estimate the elasticities of demand and supply. Instead, the elasticities are consistently estimated by exploiting the panel nature of the data set, in a way similar to Hausman and Griliches's (1986) approach to overcome errors-in-variables problems. The method can be interpreted as a generalization of Leamer's (1981) time-series estimation of a system of equations. To achieve identification, which is usually impossible using time-series data only, ${ }^{25}$ Feenstra (1994) exploits the cross-country dimension of the panel.

Leamer (1981) has shown that if the demand and supply equations have an independent error structure, the set of possible maximum likelihood estimates of the demand and supply elasticities lie on a hyperbola defined by the second moments of the data. As we will apply this insight to achieve identification of our system, it is convenient to write (15) and (16) in a way that random terms are eliminated so that unobservable terms are independent across equations. For this reason, we choose a reference country, $k$, and take differences in demand and supply relative to the reference country:

$$
\Delta \ln s_{g c t}-\Delta \ln s_{g k t}=-\left(\sigma_{g}-1\right)\left(\Delta \ln p_{g c t}-\Delta \ln p_{g k t}\right)+\tilde{\varepsilon}_{g c t}
$$

$$
\Delta \ln p_{g c t}-\Delta \ln p_{g k t}=\frac{\rho_{g}}{\left(1-\rho_{g}\right)\left(\sigma_{g}-1\right)}\left(\Delta \ln s_{g c t}-\Delta \ln s_{g k t}\right)+\widetilde{\delta}_{g c t}
$$

where $\tilde{\varepsilon}_{g c t}=\varepsilon_{g c t}-\varepsilon_{g k t}$ and $\widetilde{\delta}_{g c t}=\delta_{g c t}-\delta_{g k t}$.

\footnotetext{
${ }^{25}$ Rigobon (1999) shows that using the heteroskedasticity of one of the endogenous variables he can achieve full identification. In particular, he identifies the desired coefficients by dividing the sample into periods of high and low volatility and constraining the parameters and variances that are allowed to change across periods. Leontief (1929) had already suggested the possibility of achieving identification through splitting the data set in two parts.
} 
For a single good and a single variety, the system in (17)-(18) is reminiscent of Leamer's time series exercise. In this case, $\rho_{g}$ and $\sigma_{g}$ are not identifiable. However, Feenstra (1994) shows that by using the different varieties available per good (i.e., the cross-country dimension) and without any additional exogenous instruments $\rho_{g}$ and $\sigma_{g}$ can be identified. The first step to obtain estimates of these parameters is to transform the system in (17)-(18) into a single equation by exploiting Leamer's insight and the independence of $\tilde{\varepsilon}_{g c t}$ and $\widetilde{\delta}_{g c t}$. The second step is to provide the appropriate transformation of this equation so that the relevant coefficients can be consistently estimated.

We obtain Feenstra's first step by multiplying the error terms together, dividing by $\left(1-\rho_{g}\right)\left(\sigma_{g}-1\right)$ and rearranging,

(19) $Y_{g c t}=\theta_{1} X_{1 g c t}+\theta_{2} X_{2 g c t}+u_{g c t}$

where

(20) $\quad Y_{g c t}=\left(\Delta \ln p_{g c t}-\Delta \ln p_{g k t}\right)^{2}$

(21) $X_{1 g c t}=\left(\Delta \ln s_{g c t}-\Delta \ln s_{g k t}\right)^{2}$

(22) $X_{2 g c t}=\left(\Delta \ln p_{g c t}-\Delta \ln p_{g k t}\right)\left(\Delta \ln s_{g c t}-\Delta \ln s_{g k t}\right)$

(23) $u_{g c t}=\varepsilon_{g c t} \delta_{g c t} /\left(1-\rho_{g}\right)\left(\sigma_{g}-1\right)$

(24) $\theta_{1 g}=\rho_{g} /\left(1-\rho_{g}\right)\left(\sigma_{g}-1\right)^{2}$

(25) $\theta_{2 g}=\left(2 \rho_{g}-1\right) /\left(1-\rho_{g}\right)\left(\sigma_{g}-1\right)$

Note that estimating $\theta_{1 g}$ and $\theta_{2 g}$ (which are functions of $\rho_{g}$ and $\sigma_{g}$ ) consistently is necessary to obtain an estimate $\sigma_{g}$. However, estimating $\theta_{1 g}$ and $\theta_{2 g}$ from equation (19) gives 
inconsistent estimates as the prices and expenditure shares in $X_{l g c t}$ and $X_{2 g c t}$ are correlated with the error $u_{g c t}$. Feenstra (1994) provides a transformation of (19) that allows for the consistent estimation of $\theta_{1 g}$ and $\theta_{2 g}$. He shows that by ignoring the variations within each country over time, then the following asymptotic conditions are met

$$
E\left(\bar{X}_{1 g} \bar{u}_{g}\right)=0 ; E\left(\bar{X}_{2 g} \bar{u}_{g}\right)=0
$$

where upper bars on variables denote sample means. These conditions, combined with the assumption that the mean of the errors is independent, $E\left(\bar{u}_{g}\right)=0$, imply that the between estimator of (19) delivers consistent estimates of $\theta_{1 g}$ and $\theta_{2 g}$. Therefore, we run a weighted least square (WLS) regression on the transformed equation, ${ }^{26}$

$$
\bar{Y}_{g c t}=\theta_{1 g} \bar{X}_{1 g c t}+\theta_{2 g} \bar{X}_{2 g c t}+\bar{u}_{g c t}
$$

to obtain the between-group estimator of $\theta_{1 g}$ and $\theta_{2 g} \cdot{ }^{27}$ Feenstra (1994) also shows that the estimate of $\theta_{1 g}$ and $\theta_{2 g}$ are consistent even in the presence of measurement errors in unit values provided that a constant term is included. We therefore add a constant term when we estimate equation (27).

To relate this back to the discussion of Leamer (1981), note that by using the crosscountry dimension of the data set we can obtain a different hyperbola of supply and demand elasticities for each supplying country. Moreover, given that each country faces the same elasticity of demand for a given product (due to the CES structure), and has a common elasticity of supply (by assumption), the multiple hyperbolas describe the same underlying parameters.

\footnotetext{
${ }^{26}$ This estimator corresponds to Hansen's (1982) generalized method of moments.

${ }^{27}$ Feenstra (1994) also provides a different estimation method to obtain estimates for the demand and supply elasticities. The method is based on using dummy variables as instruments on equation (19). We refer to his paper for details.
} 
The intersection of these hyperbolas will then define estimates for the demand and supply elasticities. Since the hyperbolas will not generally intersect at a point, the WLS-between estimator serves the purpose of minimizing the appropriate sum of squared distances to the hyperbolas to choose among the possible elasticity pairs.

There is one special case in which this methodology may fail to obtain separate estimates for $\theta_{1 g}$ and $\theta_{2 g}$. Almost trivially, if $\bar{X}_{1 g c t}$ and $\bar{X}_{2 g c t}$ are asymptotically collinear, then both estimates cannot be separately obtained from (27). Feenstra (1994) shows that the regressors are not collinear asymptotically if the relative variance of demand and supply equations across countries is required to be different. Formally, there has to exist $i \neq k$ and $j \neq k$ such that the following condition is met:

$$
\frac{\sigma_{\varepsilon i}^{2}+\sigma_{\varepsilon k}^{2}}{\sigma_{\varepsilon j}^{2}+\sigma_{\varepsilon k}^{2}} \neq \frac{\sigma_{\delta i}^{2}+\sigma_{\delta k}^{2}}{\sigma_{\delta j}^{2}+\sigma_{\delta k}^{2}} \cdot{ }^{28}
$$

In terms of Leamer's hyperbola, the failure of this condition implies that the hyperbola defined by each country is asymptotically identical. This implies that we are back to Leamer's original problem and the cross-section dimension of the panel provides no additional information to identify the demand and supply elasticities separately.

Finally, to obtain the estimates of $\sigma_{g}$ requires solving for the values of $\rho_{g}$ and $\sigma_{g}$ using (24), (25) and the consistent and efficient estimates $\hat{\theta}_{1 g}$ and $\hat{\theta}_{2 g}$. As these equations are quadratic expressions of $\rho_{g}$ and $\sigma_{g}$, solutions are not unique and may be imaginary. The non-uniqueness is solved by constraints that $\sigma_{g}$ has to exceed unity and $\rho_{g}$ has to lie in the interval $[0,1)$. Imaginary solutions, however, represent a limitation of this estimation method. We provide a

\footnotetext{
${ }^{28}$ See Feenstra (1994) for the derivation of this condition.
} 
solution to the problem of imaginary numbers below. Proposition 2 presents the results in Feenstra (1994) that summarizes the possible outcomes for $\hat{\rho}_{g}$ and $\hat{\sigma}_{g}$

\section{PROPOSITION $2:^{29}$}

a) If $\hat{\theta}_{1 g}>0$ and $\hat{\theta}_{2 g}>0$, then

$$
\hat{\sigma}_{g}=1+\frac{1}{\hat{\theta}_{2 g}}\left(\frac{2 \rho_{g}-1}{1-\rho_{g}}\right) \text { where } \hat{\rho}_{g}=\frac{1}{2}+\left(\frac{1}{4}-\frac{1}{4+\frac{\hat{\theta}_{2 g}}{\hat{\theta}_{1 g}}}\right)^{\frac{1}{2}}
$$

b) If $\hat{\theta}_{1 g}>0$ and $\hat{\theta}_{2 g}<0$, then

$$
\hat{\sigma}_{g}=1+\frac{1}{\hat{\theta}_{2 g}}\left(\frac{2 \rho_{g}-1}{1-\rho_{g}}\right) \text { where } \hat{\rho}_{g}=\frac{1}{2}-\left(\frac{1}{4}-\frac{1}{4+\frac{\hat{\theta}_{2 g}}{\hat{\theta}_{1 g}}}\right)^{\frac{1}{2}}
$$

c) If $\hat{\theta}_{1 g}<0$, then estimates of $\rho_{g}$ and $\sigma_{g}$ that are both in the ranges $\hat{\sigma}_{g}>1$ and $0 \leq \hat{\rho}_{g}<1$ cannot be obtained.

Proposition 2 provides a formula linking the estimated coefficients $\hat{\theta}_{1 g}$ and $\hat{\theta}_{2 g}$ with the desired elasticity of substitution, $\sigma_{g}$. However, condition c is satisfied quite frequently and in this case Feenstra's estimation technique cannot be used to obtain estimates for $\rho_{g}$ and $\sigma_{g}$ that satisfy the economic restrictions imposed over these coefficients. We propose a procedure that

\footnotetext{
${ }^{29}$ See the appendix of Feenstra (1994) for a proof of this proposition.
} 
deals with this problem. The basic approach is to maximize the likelihood function associated with equation (27) over the set of plausible parameter values. To put this more concretely, if our unconstrained estimates satisfy the condition that $\hat{\theta}_{1 g}<0$, we conduct a grid search that finds the minimum sum of weighted least squares of residuals $\bar{u}_{g c}$ over the values of $\sigma_{g}$ and $\rho_{g}$ that are

in the ranges $\hat{\sigma}_{g}>1$ and $0 \leq \hat{\rho}_{g}<1$. In particular, we evaluate this sum for values of $\sigma_{g} \in(1,80]$ at intervals that are 5 percent apart, and for 30 different values of $\rho_{g}$ evenly spaced between 0 and 1 . The combination of $\hat{\sigma}_{g}$ and $\hat{\rho}_{g}$ that minimizes this sum is used for those goods that fail to satisfy conditions a) or b) from Proposition 2.

\section{VI) Results}

Our estimation strategy involves four stages. First, we need to obtain estimates of the elasticity of substitution, $\sigma_{g}$, by estimating equation (27). Second, we obtain estimates of how much variety changed by calculating the $\lambda_{g}$ ratio for every good $g$, which tells us the raw change in variety (see equation (9)). Third, by combining our estimates of the elasticity of substitution, we obtain an estimate of how much the exact price index for good $g$ moved as a result of the change in the number of varieties. Finally, we can apply the ideal log weights to the price movements of each good in order to obtain an estimate of the movement of the aggregate price of imports. Once we know how much import prices have changed, it is simple to apply equation (12) to calculate the welfare gain or loss from these price movements. 


\section{a) Elasticities of Substitution}

We now turn to our estimation of the elasticities of substitution. Given the tens of thousands of elasticities we estimate, it is impossible to report all of the results here. However, we can provide some sample statistics that can shed light on the plausibility of our estimates. There are three main priors that we have about these parameters. The first is that as we disaggregate, varieties are increasingly substitutable. In other words, to give a concrete example, varieties of the 3-digit category of fruit and vegetables are likely to be less substitutable than varieties of the 5-digit subcategory that only contains fresh, dried, or preserved apples. Similarly, varieties within this 5-digit sector are likely to be still less substitutable than varieties in the 8digit subcategory containing just fresh apples. Second, since a firm markup in the Krugman model equals $\sigma_{g} /\left(\sigma_{g}-1\right)$, we would like our estimates of $\sigma_{g}$ to yield plausible estimates of firm markups. Finally, we would like the goods with high elasticities of substitution to correspond to goods that we think of as less differentiated.

Equation (27) can be estimated at various levels of aggregation, and we report sample statistics for our elasticity estimates in Table $4 .{ }^{30}$ The results reveal that for both time periods, as we disaggregate product categories, varieties appear to be closer substitutes. For instance, the simple average of the elasticities of substitution is roughly 12 for 8-digit (TSUSA) goods during 1972-1988, while only 6 at the 3-digit level. For the period between 1990 and 2001, the average elasticity was around 8 for 10-digit (HTS) goods and 4 within 3-digit goods. In terms of medians, the elasticity falls less dramatically, from 3.6 and 3.0 at the lowest levels of disaggregation in the 
first and second period, respectively, to 3.0 and 2.7. In sum, depending on the statistic being used, the elasticities of substitution fall by 10 to 50 percent as we move from highest to lowest level of disaggregation in Table 4. Note also that the elasticities of substitution for a given disaggregation level seems to fall over time. This finding is robust at all product levels, and may represent increasing differentiation among tradable goods in the latter period. ${ }^{31}$

Table 4 also shows that the median elasticities are substantially lower than the weighted (and simple) average. We expect this difference since by construction the elasticities have a lower bound of one and no upper bound. Indeed, a few very large elasticities account for most of the differences. ${ }^{32}$ However, despite the big effect that these large estimates have in the average statistics, it is important to underscore the small difference that an elasticity of 20 rather than 1000 can make on the impact of variety changes on welfare. For instance, an increase in variety of 10 percent reduces a good's exact price index by only 0.4 percentage points more if variety increases are in the good with $\sigma_{g}=20$ rather than in one with $\sigma_{g}=1000$. The impact on markups is larger, however, as the markup falls from roughly 5 percent when $\sigma_{g}=20$ to less than 0.1 percent when $\sigma_{g}=1000$.

Table 5 shows the elasticities of substitution for the 20 largest SITC- 5 sectors in US imports in each of the periods. For the period between 1972 and 1988 the sector with the highest elasticity of substitution among this group was that of crude petroleum and shale oil. The

\footnotetext{
${ }^{30}$ A clarification can be handy to understand notation. When we estimate $\sigma_{\mathrm{g}}$ at the SITC-5 level, then c actually stands for the pair country-TSUSA goods. For instance, if two different TSUSA categories (eg., Apples and Kiwis) belong to a given SITC-5 category (Fresh Fruit), then if the same country (Argentina) exports in the two TSUSA categories, the two pairs (Apples from Argentina and Kiwis from Argentina) will be treated as two different varieties of the same SITC-5 category (Fresh Fruit).

${ }^{31}$ The total number of elasticities being estimated at the TSUSA/HTS level is smaller than the total number of TSUSA/HTS available within each period. This responds to the fact that the US imports in a number of categories from a small number of countries and we require at least 3 countries per category to identify parameters.

${ }^{32}$ Examples at the SITC-5 level are Crude Petroleum Testing Under 25 Degrees Api with $\sigma=28.4$ and a special type of passenger vehicles (Pass Mtr Veh, with Spark Ignition, 4 CYL, Not Elsewhere Specified) with $\sigma=1196$.
} 
estimated sigma for this sector was 9.7, almost five times larger than the sigma for Footwear $\left(\sigma_{\text {footwear }}=2.0\right)$, the sector with the smallest elasticity among the largest sectors. In the latter period, we also find that sectors related to petroleum have the highest elasticities. More generally, a comparison of elasticities of substitution across categories shows an intuitive pattern and sigmas that are in the realm of realistic values. For instance, using detailed market-level data Berry, Levinsohn, and Pakes (1995) and Goldberg (1995) find markups for the automobile industry similar to those implicit in Table $5 .{ }^{33}$ Berry et al (1995) find an average markup on the US passenger car market between 20 and 40 percent during 1971-1990. Goldberg (1995) uses a different framework to analyze the same data and obtains average markups for foreign automobiles of over 35 percent, ranging from 20 to 60 percent. Our estimates suggest markups for a broader class of motor vehicles (i.e., SITC-5 78100) of around 75 percent in the earlier period and 29 percent for the period 1990-2001 ( $\sigma=2.3$ and $\sigma=4.5$, respectively). This suggests that the sigmas we obtain for this large sector of imports is consistent with those implied by more detailed micro-econometric analysis. Moreover, the pattern of falling markups observed across time for motor vehicles is consistent with evidence by Petrin (2002) on markups on minivans and other passenger cars. ${ }^{34}$

Another way to establish the reasonableness of the estimates is to examine how well they correspond to other measures of homogeneous and differentiated goods. Rauch (1999) divided goods into three categories - commodities, reference priced goods, and differentiated goods -

\footnotetext{
${ }^{33}$ Both studies use a large set of vehicle and household characteristics to estimate the elasticity of demand by car size and country of origin (domestic or foreign) from the Consumer Expenditure Survey. The methods used in these papers differ from ours as they work with micro-data. Berry et al. estimate an instrumented random coefficients model, while Goldberg uses a nested-logit choice model and, on the supply side, a model of oligopoly with different levels of differentiation.

${ }^{34}$ Note that the fall in markups through time (or rise in elasticities of substitution) is not a characteristic of the median or average good in our overall sample (see Table 4).
} 
based on whether they were traded on organized exchanges, were listed as having a reference price, or could not be priced by either of these means. Commodities are probably correlated with more substitutable goods, but one should be cautious in interpreting commodities as perfect substitutes or the classification scheme as a strict ordering of the substitutability of goods. For example, although tea is classified by Rauch as a commodity, it is surely quite differentiated. Similarly, it is hard to see why a commodity like "dried, salted, or smoked fish" would be more homogeneous than a referenced priced good like "fresh fish" or a differentiated good like "frozen fish". That said, it would be disturbing if we did not find that goods traded on exchanges were not more substitutable than those that are not.

In Table 6 we report the results from grouping the TSUSA/HTS elasticities of substitution according to Rauch's classification. The most striking feature of the table is that in both time periods, the average elasticities of substitution are much higher for commodities than for differentiated or reference priced goods. Similarly, the median elasticities of substitution are higher for commodities than either for referenced priced or differentiated goods. This suggests that goods that Rauch classifies as commodities are more likely to have high elasticities of substitution than goods that are classified as reference priced or differentiated.

\section{b) Growth in Varieties}

Now that we have established that our estimates of the elasticities of substitution appear to be plausible by a number of criteria, we turn to the task of correctly evaluating changes in variety. One of the major obstacles we face in implementing this procedure is in the calculation of the $\lambda_{g}$ ratio. Evaluating the impact on price of a new variety is straightforward to do in cases in which the US imports other varieties of the same TSUSA/HTS category. Unfortunately, the $\lambda_{g}$ 
ratio is undefined in cases where there are no common varieties of the TSUSA/HTS category between the start and end period (i.e., $I_{g}=\varnothing$ in Proposition 1). The reason why the $\lambda_{g}$ ratio is undefined is that we cannot value the creation or destruction of a variety without knowing something about how this affects the consumption of other varieties. To give an example drawn from our data, we cannot value the invention of CD players for car radios without knowing how these new goods affected other goods, say, simple car radios. Our solution to this problem is to assume that whenever a new variety is created within an 8- or 10-digit category for which $I_{g}=\varnothing$ then all 8 - or 10-digit categories within the same 5-digit category have a common elasticity of substitution. In other words, in these special cases, the elasticity we use to evaluate the impact of a new variety being imported on the price level is a weighted average of the substitutability of other goods and varieties within the same 5-digit category. Similarly, in cases where the entire 5-digit category is new, we assume a common elasticity at the 3 -digit level. ${ }^{35}$

There are two important implications of this procedure for our results. The first is that the restriction on the set of goods for which we can calculate $\lambda$ ratios means that instead of defining all goods at the TSUSA/HTS level we need to aggregate some of these categories into 5-digit and 3-digit categories. Because of this necessary aggregation, instead of defining 12219 goods in the earlier period and 14549 goods for 1990-2001 (i.e., all TSUSA/HTS categories for which we have $\sigma \mathrm{s}$ ), ${ }^{36}$ we can only use 702 and 1501 goods (a combination of TSUSA/HTS, SITC-5 and SITC-3), respectively. Note, however, that this affects the way varieties are aggregated into goods but not the total number of varieties being used, which remains unchanged at over 150,000

\footnotetext{
${ }^{35}$ Note also that this approach also eliminates the bias arising from arbitrary re-categorization of goods since new goods simply appear as new varieties of existing goods.

${ }^{36}$ These are the numbers of available elasticities of substitution at the TSUSA and HTS level, respectively.
} 
and 250,000 in the period 1972-1988 and 1990-2001, respectively. Moreover, we need to stress that this represents vastly more disaggregated data than has been used in the past. Whether this data limitation introduces a bias into our estimates is harder to assess. Since our calculation of the $\lambda$ ratio is robust to many processes that cause existing categories to split or merge, if statistical agencies are simply changing the definitions of 8- or 10-digit categories within a larger aggregate, this is unlikely to have an impact on our results. For instance, if a TSUSA good is split into two goods within the same SITC- 5 category, then it is easy to show that $\lambda$ ratios will be unaffected by this change (as they should be). By contrast, if the simple number of varieties were used, then we would wrongly treat this change as an increase in variety. ${ }^{37}$

Table 7 shows descriptive statistics for all the existing $\lambda$ ratios with the definition of a good corresponding to a different level of aggregation. For example, in the first column of Table 7 a good corresponds to an 8- or10-digit category and a variety is an 8- or 10-digit import from a particular country. In the second and third columns, the definition of a good moves to a 5- digit and then 3-digit category while varieties continue to be 8- or 10-digit imports from a particular country. As mentioned above, if we confine ourselves to 5-, 8-, or 10-digit data, many $\lambda$ ratios are undefined as there is no common set of varieties available between the beginning and end periods. ${ }^{38}$ This tends to bias the calculations of the $\lambda$ ratios towards unity since we cannot calculate $\lambda$ ratios when a good or category appears (or disappears). As a result, the first two columns of Table 7 tell us the $\lambda$ ratios for common goods at various levels of aggregation. If we

\footnotetext{
${ }^{37}$ In the more special case were goods are split into different SITC-5 categories, it is easy to show that the $\lambda$ ratios would find less growth in varieties than the true growth.

${ }^{38}$ Note that the total number of $\lambda$ ratios exceeds the number that we ultimately use. This is because there are many TSUSA/HTS categories for which we can compute $\lambda$ ratios, but that belong to an SITC-5 category for which not all TSUSA/HTS in it have $\lambda$ ratios. For instance, if two TSUSA categories, say red and white wine belong to the same SITC- 5 category, wine, and we can obtain a $\lambda$ ratio for red wine but not for white wine, then we cannot use the $\lambda$ ratio for red wine in our calculations. We can only use the $\lambda$ ratio for the broader SITC- 5 category (i.e., wine) that encompasses both red and white varieties.
} 
define $\lambda$ ratios at the 3-digit level, we no longer have the problem of not being able to calculate $\lambda$

ratios for particular goods (since no 3-digit category appears or disappears), and hence our sample statistics correspond to the complete set of imports. As the table indicates, even when using $\lambda$ ratios to measure variety growth, the typical sector saw the number of imported varieties increase regardless of the level of aggregation. Of course, this result is most pronounced when we define goods at the 3-digit level because we do not need to drop categories that contain entirely new varieties.

This table highlights the importance of using $\lambda$ ratios rather than relying on count data to measure variety growth. As shown in Table 1, the median number of varieties per TSUSA good increased by 50 percent in the period between 1972 and 1988. In turn, the median number of HTS varieties rose by 20 percent during 1990-2001. However, when we correctly account for the fact that varieties are not symmetric in the data, we find that the appropriate magnitudes of variety growth are substantially smaller. If we focus on $\lambda$ ratios calculated using SITC-3 digit data (so that we do not have any undefined $\lambda$ ratios), we find that the median measure of variety growth is approximately 20 percent $(\lambda$ ratio $=0.80)$ in the period between $1972-1988$ and 6 percent $(\lambda$ ratio $=0.94)$ in the latter period. This suggests that by counting the number of varieties one would overestimate the true growth in variety by a factor of three! Moreover, this underscores the importance of carefully measuring variety growth when making price and welfare calculations.

\section{c) Import Prices and Welfare}


We are now ready to use the elasticities of substitution to evaluate the price effects of changes in varieties. Aggregating together our $\lambda$ ratios according to equation (12) yields estimates of the impact of variety growth on the exact import price index. The results from this exercise are reported in Table 8 . Overall, variety growth implies that the variety adjusted unit price for imports fell 22.5 percent faster than the unadjusted price between 1972 and 1988 or about 1.6 percent per year. Interestingly, the impact of variety growth was much smaller during the 1990s. Between 1990 and 2001, the growth of varieties meant that the exact price index fell 5 percent faster than the unadjusted index over this time period or about 0.5 percent per annum. The lower rate of decline in the later period may reflect the fact that much of the gains from globalization arising from rise in importance of East Asian trade may have been realized prior to 1990. Throughout the entire period we find that the growth of varieties reduces the exact price relative to conventionally measured import price index by 28.1 percent.

It is difficult to find a benchmark with which to compare our results. We are not aware of any study that measures the impact of variety on aggregate prices, and the papers that study a single good at the micro-level (or at most a few goods) are not suitable for this comparison. Given the lack of aggregate effects of variety in the literature, we will use as a reference the effects that other sources of bias (quality change, outlet substitution, etc.) have on the overall consumer price index. In mid-1995 a commission was appointed to study the potential biases in the existing measurement of the Consumer Price Index. This CPI Commission concluded that the change in the consumer price index overstates the change in the cost of living by about 1.1 percentage points per year (Boskin et al., 1996). Several sources of bias are considered, but the main source is the incorrect measurement of quality change of products. The effect of quality change alone can account for about 0.6 percentage points in the overall index. These numbers 
suggests that the bias that we find in the import price index only as a result of the unaccounted variety growth is very large. That is, the bias due to variety growth in the import price index is twice as large as the bias induced by quality change in the overall price index and as large as the total bias from all sources.

We now turn to calculating the welfare effect of the fall in the US exact import price. Not surprisingly, the magnitude of the welfare gain from this fall hinges on the functional forms underlying the Dixit-Stiglitz structure and cannot be general. If elasticities of substitution are not constant or if marginal costs are not fixed, theory suggests that one can obtain higher or lower estimates of the gains from variety. Although our estimate of the impact of imported varieties on import prices is correct for any domestic production structure, we cannot translate this into a welfare gain without making explicit assumptions about the structure of domestic production. Our choice is to assume the same structure of the US economy as in Krugman (1980). We do this for two reasons. First, since this is the dominant model of varieties, it provides a useful benchmark for understanding the potential welfare gains. Second, we lack the necessary data and model of the economy's input-output linkages to estimate variants of the monopolistic competition model in which there are more complex interactions between imported and domestic varieties.

These concerns notwithstanding, one of the strengths of our analysis is that we can be almost completely agnostic about the causes of the increase in imported varieties. Presumably the causes are some combination of reductions in trade costs and growth in foreign output. Moreover, since we will use ideal weights to calculate the impact of price changes on welfare, a shift in preferences in favor of imports will not bias our welfare calculations. ${ }^{39}$

\footnotetext{
${ }^{39} \mathrm{We}$ do need to maintain the assumption that tastes have not shifted in favor of the imports from one country relative to another country.
} 
Equations (11) and (12) show that the change in welfare that results from changes in varieties in imported goods can be calculated as the fraction of imported goods in total consumption goods, $(1-\alpha)$, times the product of the weighted $\lambda$ ratios. In particular, we use the average import share in each period, 8.1 percent for 1972-1988 and 11.7 percent for 1990-2001, respectively, together with the information in Table 8 to obtain the gains in welfare due to variety. We find that real income has increased by 2.82 percent solely as a result of the changes in varieties. Around 2.03 percentage points accrue to the earlier period. These gains from variety are 3 to 6 times larger than the estimated gains from eliminating protectionism (e.g., Krugman (1990), Feenstra (1992) and Romer (1994)) and around 10 times larger than the estimated gains from eliminating business cycles (Alvarez and Jermann (2000)). Our estimates are in line with the calculations from Feenstra (1992), that suggests that a halving of varieties (in a symmetric world) would reduce world welfare between 2 and 8 percent. The estimates we find are smaller than those calculated by Romer (1994) for a small open economy. We will discuss below the sources of this difference.

\section{d) Robustness of results to alternative assumptions}

In the previous section we computed the impact of variety growth of US imports on aggregate welfare. Our computation required several weaker assumptions than those present in previous numerical exercises. First, we do not require that varieties or goods have equal shares in consumption. Second, we allow for different elasticities of substitution for each of the 2203 goods used. Third, we obtain our elasticities of substitution by allowing each of our 2203 markets to have a different elasticity of supply rather than assuming that these supply elasticities are always equal to zero. Table 9 underscores the importance of using this weaker set of 
assumptions. As mentioned in Section V, when import shares are assumed equal for all varieties, the aggregate bias in equation (12) becomes $\prod_{g \in G}\left(\frac{V_{g t-1}}{V_{g t}}\right)^{\frac{w_{g t}(G)(1-\alpha)}{\sigma_{g}-1}}$, where $\frac{V_{g t-1}}{V_{g t}}$ is the ratio of the actual number of varieties in each period. Column 2 of Table 9 shows how the impact of variety on welfare is affected by using a simple count of varieties (i.e., the $V$ ratios) rather than the appropriate $\lambda$ ratios. By using $V$ ratios the welfare gains from variety growth become 6.52 percent, more than twice as big as the true estimate using $\lambda$ ratios. This suggests that in the case of US imports, using a simple count of varieties to measure the impact of variety growth grossly overestimates the true impact.

Column 3 of Table 9 shows the additional impact of using a single elasticity of substitution for all varieties. We choose Hummels' (1999) commonly used elasticity of 2.9 as a benchmark. The impact of variety using the single elasticity of 2.9 is 5.37 percent, smaller than that of column 2. This underscores the importance of using the full distribution of sigmas to value variety since despite using a smaller point estimate of the average elasticity (relative to columns 1 and 2) we find that the impact of variety on welfare is reduced. ${ }^{40}$ Finally, column 4 shows the effect of a reduction in the average elasticity of substitution on welfare. By reducing the average from 2.9 to 2.0 (as used in Romer (1994)), the impact on welfare significantly rises to 8.47 percent. In sum, columns 2-4 quantify the importance of using $\lambda$ ratios and a complete distribution of sigmas to calculate the impact of variety growth on welfare. 
It is important to assess the sensitivity of our estimates to two key assumptions of our framework. First, in our analysis all imported goods are assumed to be for final consumption. This is not the case in the data, as almost two thirds of imports are intermediate or capital goods and not final consumption goods. As noted by Romer (1994), however, the Dixit-Stiglitz structure allows for new varieties to be modeled either as consumption goods, as in Grossman and Helpman (1992), or as intermediate inputs in production, as in Romer (1990), with no fundamental change in the underlying economic analysis. In other words, treating the share of imported intermediate goods as final consumption does not necessarily bias our estimates. The case of capital goods is different. While consumption varieties only offer a static gain, the potential gains from variety growth in capital goods can have persistent effects in time. This has the potential of magnifying the effects of variety growth on welfare relative to our "static" results. Therefore, treating capital goods as final consumption seems to imply that we are understating the true gains from variety.

The second assumption that is important for our results is that of Krugman's (1980) production structure. This structure assumes that domestic varieties are unaffected by new foreign varieties (as in Romer (1994) and Klenow and Rodriguez (1997)). However, if domestic varieties were affected by imported varieties, then our welfare calculations would change. The relationship between domestic and foreign varieties is complex to model, but several different strategies exist in the literature. Rutherford and Tarr (2002) develop a model for a small open economy in which domestic varieties are partially substituted by imported varieties when tariffs on imported goods fall. If this were the case in the US, our estimates may be overestimating the true gains from variety. By contrast, in a model with vertical specialization and differentiated

\footnotetext{
${ }^{40}$ This reveals that sectors with high variety growth seem to be associated with low elasticity of substitutions.
} 
products, increases in imported intermediate varieties can lead to new domestic varieties. ${ }^{41}$ In this world, our welfare results would underestimate the true gains from variety.

\section{VII) Conclusion}

Understanding the impact of new products and the growth in varieties on economies has been one of the central questions in international economics, regional economics, and macroeconomics. Until now, attempts to estimate magnitude of these effects have been limited to extremely careful econometric studies of particular cases and attempts to calibrate standard models. The failure to obtain credible estimates of the impact of new goods and varieties on prices and welfare at the national level has stemmed from the difficulty of implementing careful econometric studies of particular markets more broadly and from the implausibility of many assumptions underlying calibration exercises.

This paper is the first attempt to implement a methodology that estimates all of the parameters necessary to calculate an exact price index and perform welfare calculations at the national level. This, of course, does not obviate the need for careful econometric studies of entry in particular markets. Indeed, we see this work as complementary to ours. In markets where sufficient data exist to obtain better estimates of price effects due to entry, one should do so. Indeed, one could imagine more precise estimates of the impact of new goods and varieties arising from a hybrid technique in which certain markets are modeled in detail and others are modeled according to our implementation of the Feenstra index. Whether that would substantially alter our results is impossible to say, but the fact that our estimates seem close to those obtained from careful market studies of passenger cars, suggests that the errors in our estimates would not substantively affect the conclusions.

\footnotetext{
${ }^{41}$ For instance, in many countries, without imported parts domestic cars would not be produced (or consumed).
} 
Our results indicate that the effect of new goods and varieties on the US economy is large. By ignoring these effects, the US import price index overstates import price inflation by 1.2 percent per year. If the bias in the CPI is comparable to the bias in the import price index, then this suggest that the biases identified in this paper are not only more important than hedonic adjustments, they are more important than all other biases combined. Obviously more work needs to be done to understand whether the biases in the import price index are similar in magnitude to those in the CPI, but the results suggest that there is enormous potential for very large effects.

Finally, our results suggest that globalization has had very substantial impacts on welfare through the import of new varieties. US welfare is 3 percent higher due to gains accruing from the import of new varieties. An important qualification is that our estimates are obtained by assuming the US economy can be modeled as in Krugman (1980). While this is a sensible benchmark, there clearly is a need for better modeling and estimation of dynamic and inputoutput effects arising from increases the number of varieties. Even so, our estimation indicates that the gains from trade first suggested by Krugman a generation ago are quite important in reality. 


\section{References}

Armington, Paul S. "A Theory of Demand for Products Distinguished by Place of Production." International Monetary Fund Staff Papers, March 1969, 16(1), pp. 159-78.

Berry, S., Levinsohn, James and Pakes, Ariel. "Automobile Prices in Market Equilibrium." Econometrica, July 1995, 63(4), pp. 841-90.

Brown, Drusilla, Alan V. Deardorff, and Robert M. Stern, "Modeling Multilateral Trade Liberalization in Services," Jul. 6, 1995. Asia-Pacific Economic Review, April, 1996.

Diewert, W. E. "Exact and Superlative Index Numbers." Journal of Econometrics, May 1976, 4(2), pp. 115-45.

Dixit, Avinash K. and Stiglitz, Joseph E. "Monopolistic Competition and Optimum Product Diversity." American Economic Review, June 1977, 67(3), pp. 297-308.

Eaton, Jonathan and Kortum, Samuel. "Technology, Geography, and Trade.” Econometrica, September 2002, 70(5), pp. 1741-79.

Feenstra, Robert C. "How Costly Is Protectionism?” Journal of Economic Perspectives, Summer 1992, 6(3), pp. 159-78.

. "New Product Varieties and the Measurement of International Prices." American Economic Review, March 1994, 84(1), pp. 157-77.

. "U.S. Imports, 1972-1994: Data and Concordances.” National Bureau of Economic Research Working Paper No. 5515, March 1996.

Fujita, Masahisa; Krugman, Paul; Venables, Anthony J. The Spatial Economy: Cities, Regions, and International Trade. Cambridge and London: MIT Press, 1999.

Goldberg, Pinelopi Koujianou. "Product Differentiation and Oligopoly in International Markets: The Case of the U.S. Automobile Industry.” Econometrica, July 1995, 63(4), pp. 891951.

Grossman, Gene M. and Helpman, Elhanan. Innovation and Growth in the Global Economy, Cambridge, Mass. and London: MIT Press, 1991.

. "Product Development and International Trade." Journal of Political Economy, December 1989, 97(6), pp. 1261-83.

Griliches, Zvi and Hausman, Jerry A. "Errors in Variables in Panel Data.” Journal of Econometrics, February 1986, 31(1), pp. 93-118. 
Hansen, Lars Peter. "Large Sample Properties of Generalized Method of Moments Estimators." Econometrica, July 1982, 50(4), pp. 1029-54.

Hausman, Jerry A. "Exact Consumer's Surplus and Deadweight Loss." American Economic Review, Sept. 1981, 71(4), pp. 662-76.

. "Valuing the Effect of Regulation on New Services in Telecommunications." Brookings Papers on Economic Activity, Microeconomics, 1997, 0(0), pp. 1-38.

. "Valuation of New Goods Under Perfect and Imperfect Competition. The Economics of New Goods." National Bureau of Economic Research Studies in Income and Wealth, Vol. 58. Chicago and London: University of Chicago Press, 1997, pp. 209-37.

Helpman, Elhanan and Krugman, Paul R. Trade policy and market structure. Cambridge, Mass. and London: MIT Press, 1989.

Hummels, David. “Toward a Geography of Trade Costs,” University of Chicago, mimeo, 1999.

Hummels, David and Peter J. Klenow. “The Variety and Quality of a Nations Exports." Purdue University, mimeo, December 2002.

Klenow, Peter J. and Andres Rodriguez-Clare. "Quantifying Variety Gains from Trade Liberalization” mimeo September 1997.

Krugman, Paul R. "Increasing Returns, Monopolistic Competition, and International Trade." Journal of International Economics, Nov. 1979, 9(4), pp. 469-79.

. "Scale Economies, Product Differentiation, and the Pattern of Trade." American Economic Review, Dec. 1980, 70(5), pp. 950-59.

Lancaster, Kelvin. "Socially Optimal Product Differentiation.” American Economic Review, September 1975, 65(4), pp. 567-85.

Leamer, Edward E. "Is It a Demand Curve, or Is It a Supply Curve? Partial Identification through Inequality Constraints." Review of Economics and Statistics, August 1981, 63(3), pp. 319-2.

Petrin, Amil. "Quantifying the Benefits of New Products: The Case of the Minivan." National Bureau of Economic Research Working Paper No. 8227, April 2001.

Rauch, James E. "Networks versus Markets in International Trade.” Journal of International Economics, June 1999,48(1), pp. 7-35.

Rigobon, Roberto and Sack, Brian. "Measuring the Reaction of Monetary Policy to the Stock Market.” Quarterly Journal of Economics, May 2003,118(2), pp. 639-69. 
. "On the Measurement of the International Propagation of Shocks." National Bureau of Economic Research Working Paper No. 7354, September 1999.

Romer, Paul M. "Capital, Labor, and Productivity." Brookings Papers on Economic Activity, Special Issue, 1990, 0(0), pp. 337-67.

. "New Goods, Old Theory, and the Welfare Costs of Trade Restrictions." Journal of Development Economics, February 1994, 43(1), pp. 5-38.

Rutherford, Thomas F. and Tarr, David G. "Trade Liberalization, Product Variety and Growth in a Small Open Economy: A Quantitative Assessment." Journal of International Economics, March 2002, 56(2), pp. 247-72.

Sato, Kazuo. "The Ideal Log-Change Index Number." Review of Economics and Statistics, May 1976, 58(2), pp. 223-28.

Spence, Michael. "Product Differentiation and Welfare." American Economic Review, May 1976, 66(2), pp. 407-14. 
Table 1: Variety in US Imports (1972 - 2001)

US Imports 1972-1988

\begin{tabular}{|c|c|c|c|c|c|c|c|}
\hline & Year & $\begin{array}{c}\text { Number of } \\
\text { Goods }\end{array}$ & $\begin{array}{l}\text { Median Number } \\
\text { of Exporting } \\
\text { Countries }\end{array}$ & $\begin{array}{l}\text { Average Number } \\
\text { of Exporting } \\
\text { Countries }\end{array}$ & $\begin{array}{l}\text { Total Number of } \\
\text { Varieties (country- } \\
\text { good pairs) }\end{array}$ & $\begin{array}{l}\text { Average Value } \\
\text { per Variety (in } \\
1990 \text { million } \\
\text { dollars) }\end{array}$ & $\begin{array}{l}\text { Share of Total US } \\
\text { Imports in year }\end{array}$ \\
\hline & $(1)$ & $(2)$ & $(3)$ & $(4)$ & $(5)$ & $(6)$ & $(7)$ \\
\hline All 1972 goods & 1972 & 7731 & 6 & 9.7 & 74667 & 2.92 & 1.00 \\
\hline All 1988 goods & 1988 & 12822 & 9 & 13.6 & 173937 & 2.67 & 1.00 \\
\hline Common 72-88 & 1972 & 4171 & 6 & 8.7 & 36191 & 2.31 & 0.48 \\
\hline Common 72-88 & 1988 & 4171 & 10 & 13.5 & 56183 & 2.24 & 0.32 \\
\hline 1972 not in 1988 & 1972 & 3560 & 7 & 10.8 & 38476 & 3.49 & 0.52 \\
\hline 1988 not in 1972 & 1988 & 8651 & 8 & 13.6 & 117754 & 2.88 & 0.68 \\
\hline \multicolumn{8}{|c|}{ US Imports 1990-2001 } \\
\hline & Year & $\begin{array}{c}\text { Number of } \\
\text { Goods }\end{array}$ & $\begin{array}{l}\text { Median Number } \\
\text { of Exporting } \\
\text { Countries }\end{array}$ & $\begin{array}{l}\text { Average Number } \\
\text { of Exporting } \\
\text { Countries }\end{array}$ & $\begin{array}{l}\text { Total Number of } \\
\text { Varieties (country- } \\
\text { good pairs) }\end{array}$ & $\begin{array}{l}\text { Average Value } \\
\text { per Variety (in } \\
1990 \text { million } \\
\text { dollars) }\end{array}$ & $\begin{array}{l}\text { Share of Total US } \\
\text { Imports in year }\end{array}$ \\
\hline & $(1)$ & $(2)$ & $(3)$ & $(4)$ & $(5)$ & $(6)$ & $(7)$ \\
\hline All 1990 goods & 1990 & 14572 & 10 & 12.5 & 182375 & 2.72 & 1.00 \\
\hline All 2001 goods & 2001 & 16390 & 12 & 15.8 & 259215 & 4.30 & 1.00 \\
\hline Common 90-01 & 1990 & 10636 & 10 & 12.4 & 132417 & 2.48 & 0.73 \\
\hline Common 90-01 & 2001 & 10636 & 13 & 16.3 & 173776 & 3.75 & 0.67 \\
\hline 1990 not in 2001 & 1990 & 3936 & 10 & 12.7 & 49958 & 3.34 & 0.27 \\
\hline 2001 not in 1990 & 2001 & 5754 & 11 & 14.8 & 85439 & 5.41 & 0.33 \\
\hline
\end{tabular}

Notes: For the period 1972-1988 goods are defined at the TSUSA level (8-digit). For the latter period, 10-digit HTS data is used. Source: NBER CD-ROM and http://data.econ.ucdavis.edu/international/usixd/wp5514d.html 
Table 2: Ranking in terms of Number of Goods Imported by US

\begin{tabular}{lcccc}
\hline & \multicolumn{5}{c}{ Ranking in year: } \\
\cline { 2 - 5 } Country & $\mathbf{1 9 7 2}$ & $\mathbf{1 9 8 8}$ & $\mathbf{1 9 9 0}$ & $\mathbf{2 0 0 1}$ \\
\hline JAPAN & 1 & 1 & 3 & 7 \\
UKINGDOM & 2 & 4 & 4 & 3 \\
GERMAN & 3 & 3 & 2 & 2 \\
CANADA & 4 & 2 & 1 & 1 \\
FRANCE & 5 & 6 & 5 & 6 \\
ITALY & 6 & 5 & 6 & 5 \\
SWITZLD & 7 & 11 & 11 & 11 \\
HONGKONG & 8 & 9 & 12 & 16 \\
NETHLDS & 9 & 13 & 13 & 14 \\
TAIWAN & 10 & 7 & 7 & 9 \\
SPAIN & 11 & 14 & 15 & 12 \\
BEL_LUX & 12 & 15 & 14 & 15 \\
MEXICO & 13 & 12 & 10 & 8 \\
SWEDEN & 14 & 17 & 16 & 19 \\
DENMARK & 15 & 22 & 21 & 23 \\
AUSTRIA & 16 & 18 & 18 & 21 \\
INDIA & 17 & 19 & 23 & 13 \\
KOREA_S & 18 & 8 & 9 & 10 \\
BRAZIL & 19 & 16 & 17 & 18 \\
AUSTRAL & 20 & 20 & 20 & 20 \\
ISRAEL & 21 & 21 & 22 & 22 \\
PORTUGAL & 22 & 26 & 28 & 32 \\
NORWAY & 23 & 31 & 31 & 37 \\
IRELAND & 24 & 27 & 26 & 28 \\
FINLAND & 25 & 28 & 30 & 31 \\
COLOMBIA & 26 & 33 & 34 & 35 \\
PHIL & 27 & 25 & 25 & 26 \\
CHINA & 28 & 10 & 8 & 4 \\
ARGENT & 29 & 29 & 29 & 39 \\
GREECE & 38 & 44 & 47 \\
\hline \hline NOESTOP & & 31 & \\
\hline
\end{tabular}

Notes: Top 30 countries in 1972 included. Same notes as in table 1 apply. 
Table 3: Country Contribution to Growth in US Varieties (1972-1988 / 1990-2001)

\begin{tabular}{lcclcc}
\hline \hline & $\begin{array}{c}\text { Contribution } \\
\text { Country }\end{array}$ & $\begin{array}{c}\text { Average } \\
\text { Share of US } \\
\text { Imports (1) }\end{array}$ & Country & $\begin{array}{c}\text { Average } \\
\text { Contribution } \\
1990-2001\end{array}$ & $\begin{array}{c}\text { Share of US } \\
\text { Imports (1) }\end{array}$ \\
\hline CHINA & $4.8 \%$ & $1.0 \%$ & CHINA & $5.7 \%$ & $6.0 \%$ \\
TAIWAN & $4.4 \%$ & $4.0 \%$ & INDIA & $4.4 \%$ & $0.7 \%$ \\
KOREA_S & $4.4 \%$ & $2.9 \%$ & MEXICO & $3.7 \%$ & $8.8 \%$ \\
CANADA & $4.2 \%$ & $22.7 \%$ & SPAIN & $2.9 \%$ & $0.6 \%$ \\
ITALY & $4.0 \%$ & $2.9 \%$ & S_AFRICA & $2.6 \%$ & $0.4 \%$ \\
GERMAN & $3.8 \%$ & $6.9 \%$ & ITALY & $2.6 \%$ & $2.3 \%$ \\
FRANCE & $3.8 \%$ & $2.6 \%$ & INDONES & $2.5 \%$ & $0.8 \%$ \\
JAPAN & $3.6 \%$ & $18.4 \%$ & CANADA & $2.5 \%$ & $18.7 \%$ \\
UKINGDOM & $3.5 \%$ & $4.7 \%$ & TURKEY & $2.3 \%$ & $0.3 \%$ \\
HONGKONG & $3.1 \%$ & $2.3 \%$ & THAILAND & $2.3 \%$ & $1.2 \%$ \\
MEXICO & $3.0 \%$ & $4.0 \%$ & AUSTRAL & $2.1 \%$ & $0.7 \%$ \\
SWITZLD & $2.6 \%$ & $1.1 \%$ & FRANCE & $2.1 \%$ & $2.7 \%$ \\
BRAZIL & $2.6 \%$ & $1.9 \%$ & KOREA_S & $2.0 \%$ & $3.4 \%$ \\
NETHLDS & $2.2 \%$ & $1.1 \%$ & BEL_LUX & $1.9 \%$ & $0.9 \%$ \\
THAILAND & $2.2 \%$ & $0.5 \%$ & POLAND & $1.8 \%$ & $0.1 \%$ \\
SINGAPR & $1.9 \%$ & $1.1 \%$ & MALAYSIA & $1.8 \%$ & $1.5 \%$ \\
\hline \hline
\end{tabular}

Notes: A US variety is defined as a TSUSA-country pair in 1972-1988 and HTS-country pair in 1990-2001. (1) Log ideal weights used as average shares (see text for a definition). Same notes as Table 1 apply. 
Table 4: Sigmas for different Aggregation Levels and Time Periods

\begin{tabular}{llccc}
\hline \hline Period & Statistic & TSUSA/HTS & SITC-5 & SITC-3 \\
\hline 1972-1988 & Percentile 90 & 16.0 & 10.9 & 7.0 \\
& Percentile 50 (Median) & 3.6 & 3.1 & 3.0 \\
& Percentile 10 & 1.6 & 1.7 & 1.9 \\
& Average & 11.7 & 6.4 & 5.9 \\
& Nobs of categories & 12219 & 1480 & 243 \\
& Median varieties per category (1) & 12 & 45 & 288 \\
& & & & 6.1 \\
$1990-2001$ & Percentile 90 & 14.1 & 9.7 & 2.7 \\
& Percentile 50 (Median) & 2.9 & 2.7 & 1.8 \\
& Percentile 10 & 1.5 & 1.6 & 3.9 \\
& Average & 8.2 & 5.6 & 255 \\
& Nobs of categories & 14549 & 2731 & 552 \\
\hline \hline
\end{tabular}

Notes: (1) As in Table 3, a variety is defined as a TSUSA/HTS-country pair. For the TSUSA/HTS column: number of observations is equivalent to the median number of countries. For SITC-5 (SITC-3) column it is the median number of TSUSA/HTS-good/country pairs in a given SITC-5 (SITC-3) level. 


\section{Table 5: Sigmas for the 20 SITC-5 Sectors with the Largest Import Share by Period}

\begin{tabular}{|c|c|c|c|}
\hline \multicolumn{4}{|r|}{ Period 1972-1988 } \\
\hline SITC-5 & Sigma & Average Share (in \%) & Descriptions \\
\hline 33300 & 9.66 & 10.10 & CRUDE PETROLEUM, SHALE OIL INC RECONST, TEST 25DEG API AOV \\
\hline 93100 & 8.51 & 5.11 & SPECIAL TRANSACTIONS \& COMMOD NOT CLASSIF BY KIND \\
\hline 1112 & 7.99 & 1.52 & BEEF, FRSH, OR FRZN, VEAL PREP OR PRSVD \\
\hline 76210 & 6.29 & 5.14 & RADIO TAPE PLAYER AND RECEIVERS FOR MOT VEH, NO BATTERY OPERATION \\
\hline 78210 & 5.83 & 2.35 & TRUCKS, TRACTORS W/WO TRAILER GASOLINE OR DIESEL \\
\hline 7111 & 5.31 & 2.33 & COFFEE, CRUDE \\
\hline 24822 & 4.82 & 2.15 & LUMBER (SPRUCE, PINE, PARANA, DOUG-FIR, HEMLOCK, CEDAR, ETC) WRKD OR DRSD, WOOD SIDING \\
\hline 89423 & 4.51 & 1.06 & PARTS \& ACCESSORIES OF TOYS (INFLAT, RUBBER, PLASTIC, W/SPRING MECHANISM) \\
\hline 33440 & 4.08 & 2.93 & FUEL OILS, HEAVY, CONDENSATE AND NO.4-TYPE \\
\hline 78490 & 3.00 & 2.51 & PARTS AND ACCESSORIES OF MOTOR VEHICLES, ETC \\
\hline 75200 & 2.99 & 2.17 & COMPUTERS, DATA PROCESSING MACHINES, PRINTERS AND PARTS \\
\hline 68310 & 2.84 & 1.28 & UNWROUGHT NICKEL \\
\hline 82100 & 2.74 & 1.64 & FURNITURE \& PTS; BEDS, SOFAS, CABINETS, ETC.; SEATS USED FOR MOTORVEHICLES \\
\hline 78510 & 2.58 & 1.21 & MOTORCYCLES AND CYCLES, MOTORIZED \& NOT MOTORIZED \\
\hline 64110 & 2.53 & 2.64 & NEWSPRINT PAPER \\
\hline 66729 & 2.40 & 1.22 & DIAMONDS (NO INDUST), WORKED, NOT SET, FOR JEWELRY \\
\hline 3600 & 2.23 & 1.24 & CRUSTACEAN ETC FRSH, CH, FZ, DRD, SALTED, ETC. \\
\hline 78100 & 2.29 & 19.80 & MOTOR CARS \& OTH PASSENGER VEHICLES \\
\hline 6120 & 2.21 & 1.13 & CANE/BEET SUGAR, SYRUP, MOLASSES \\
\hline 85102 & 2.02 & 2.41 & LEATHER FOOTWEAR AND SNEAKERS \\
\hline \multicolumn{4}{|r|}{ Period 1990-2001 } \\
\hline SITC-5 & Sigma & Average Share (in \%) & Descriptions \\
\hline 33411 & 9.85 & 1.17 & GASOLINE INCLUDING AVIATION (EXCEPT JET) FUEL \\
\hline 78210 & 9.83 & 3.16 & MOTOR VEHICLES FOR THE TRANSPORT OF GOODS \\
\hline 33300 & 7.24 & 15.38 & CRUDE OIL FROM PETROLEUM OR BITUMINOUS MINERALS \\
\hline 84300 & 6.37 & 1.58 & MEN'S OR BOYS' COATS, JACKETS ETC, TEXT, KNITTED \\
\hline 75270 & 5.89 & 2.52 & STORAGE UNITS FOR DATA PROCESSING SYSTEMS \\
\hline 79290 & 5.14 & 1.20 & PTS, N.E.S. AIRCRAFT \& ASSOC EQUIP; SPACECRAFT ETC \\
\hline 78100 & 4.51 & 18.59 & MOTOR CARS \& OTH MOTOR VEHICLES \\
\hline 75260 & 4.29 & 2.36 & INPUT OR OUTPUT UNITS FOR DATA PROCESSING SYSTEMS \\
\hline 24821 & 4.12 & 1.07 & CHEESE AND CURD (24) \\
\hline 34140 & 3.89 & 1.75 & TUNA, SKIPJACK/STRIPE-BELLIED BONITO FR EX LVR/ROE \\
\hline 75230 & 3.79 & 1.49 & DIGITAL PROCESSNG UNITS \\
\hline 76430 & 3.52 & 1.52 & TRANSMISSION APPARATUS FOR RADIOTELEPHONY, ETC \\
\hline 85120 & 3.41 & 2.04 & SPORTS FOOTWEAR \\
\hline 76381 & 3.13 & 1.25 & VIDEO RECORDING OR REPRODUCING APPARATUS ETC \\
\hline 93100 & 3.06 & 5.54 & SPECIAL TRANSACTIONS AND COMMODITIES NOT CLASSIFIED ACCORDING TO KIND \\
\hline 78400 & 2.68 & 3.40 & PARTS AND ACCESSORIES OF MOTOR VEHICLES, ETC \\
\hline 64110 & 2.40 & 1.17 & NEWSPRINT IN ROLLS OR SHEETS \\
\hline 76110 & 2.34 & 1.13 & TELEVISION RECEIVERS, COLOR, INCLUDING MONITORS, PROJECTORS AND RECEIVERS \\
\hline 77640 & 1.84 & 4.16 & ELECTRONIC INTEGRATED CIRCUITS \& MICROASSEMBLIES \\
\hline 77210 & 1.71 & 1.03 & ELECRICL APPARAT FOR SWITCHG OR PROTECTG ELEC CIRC (772) \\
\hline
\end{tabular}

Notes: SITC-5 Revision 2 (Revision 3) codes are used for the period 1972-1988 (1990-2001). Shares are simple averages of start and end years. Also see notes from Table 5. 
Table 6: Estimated Sigmas and Rauch Classification

\begin{tabular}{lccc}
\hline \hline & \multicolumn{3}{c}{ Rauch's Classification of Goods: } \\
& Commodity & Reference Priced & Differentiated \\
\hline & \multicolumn{3}{c}{$1972-1988$ (TSUSA) } \\
\cline { 2 - 4 } Median & 4.32 & 3.58 & 3.54 \\
Average & 13.57 & 10.22 & 11.72 \\
& & & \\
& & $1990-2001$ & (HTS) \\
IMedian & 3.10 & 2.92 & 2.92 \\
Average & 12.91 & 8.74 & 8.13 \\
\hline \hline
\end{tabular}

Notes: Rauch's (1999) classification is at the 4-digit SITC level. This table presents the median and average elasticities of substitution for the TSUSA/HTS goods within those SITC-4 classified by Rauch. 
Table 7: Descriptive Statistic of Lambda Ratios

\begin{tabular}{llccc}
\hline \hline Period & Statistic & TSUSA/HTS & SITC-5 & SITC-3 \\
\hline \multirow{2}{*}{ 1972-1988 } & Percentile 5 & 0.10 & 0.04 & 0.12 \\
& Percentile 50 & 0.92 & 0.86 & 0.80 \\
& Percentile 95 & 2.50 & 3.22 & 2.20 \\
& Nobs & 3846 & 1089 & 220 \\
$1990-2001$ & & & & \\
& Percentile 5 & 0.20 & 0.27 & 0.52 \\
& Percentile 50 & 0.97 & 0.97 & 0.94 \\
& Percentile 95 & 2.44 & 2.82 & 3.29 \\
& Nobs & 10168 & 1927 & 251 \\
\hline \hline
\end{tabular}

Notes: See text for definitions. 
Table 8: The Impact of Variety in US Import Prices

\begin{tabular}{lcc}
\hline \hline & $\begin{array}{c}\text { Ratio between Aggregate Conventional Price Index and } \\
\text { Aggregate Exact Price Index including Variety }\end{array}$ \\
\cline { 2 - 3 } $1972-1988$ & End-point Ratio & Average Per-annum Ratio \\
$1990-2001$ & 0.775 & 0.984 \\
$1972-2001$ & 0.950 & 0.995 \\
\hline \hline
\end{tabular}

Notes: This table shows the estimated values of equation (12) by period. (1) For the period between 1988 and 1990 the average per-annum rate was applied. 
Table 9: Welfare Comparisons

\begin{tabular}{|c|c|c|c|c|}
\hline & $\begin{array}{c}\text { Benchmark Estimate } \\
(1)\end{array}$ & $\begin{array}{c}\text { Equality of } \\
\text { Import Shares } \\
(2) \\
\end{array}$ & $\begin{array}{c}\text { Single Gravity } \\
\text { Sigma } \\
(3)\end{array}$ & $\begin{array}{c}\text { Smaller Median } \\
\text { Sigma } \\
(4) \\
\end{array}$ \\
\hline Number of Sigmas Used & 2203 & 2203 & 1 & 1 \\
\hline Median Sigma & 3.1 & 3.1 & 2.9 & 2.0 \\
\hline Average Sigma & 6.2 & 6.2 & 2.9 & 2.0 \\
\hline Lambda Ratio (L) or Count Data (N) & L & $\mathrm{N}$ & $\mathrm{N}$ & $\mathrm{N}$ \\
\hline Average Share (in percent) (1) & 9.2 & 9.2 & 9.2 & 9.2 \\
\hline Welfare Impact & 2.82 & 6.52 & 5.37 & 8.47 \\
\hline
\end{tabular}

Notes: (1) For expositional purposes, we present the weighted average share of imports between the periods 1972-1988 and 1990-2001. Calculations are based on each period's average share and not on this weighted average. 